Quantification of mesoscale transport

F. Gheusi et al.

\title{
Quantification of mesoscale transport across the boundaries of the free troposphere: a new method and applications to ozone
}

F. Gheusi, J.-P. Cammas, F. Cousin, C. Mari, and P. Mascart

Laboratoire d'Aérologie, Toulouse, France

Received: 17 September 2004 - Accepted: 27 October 2004 - Published: 8 December 2004 Correspondence to: F. Gheusi (ghef@aero.obs-mip.fr)

(C) 2004 Author(s). This work is licensed under a Creative Commons License.

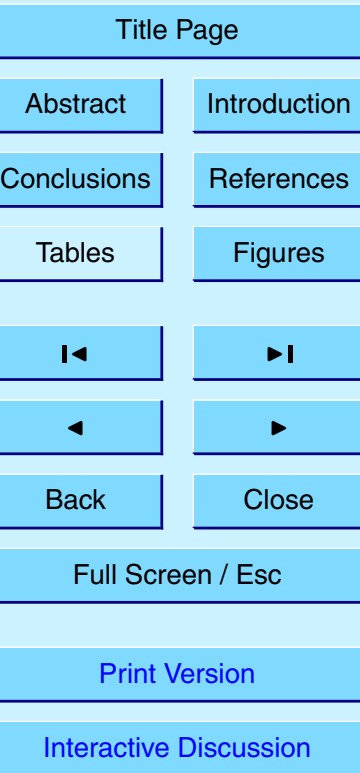

EGU 


\section{Abstract}

A new Lagrangian method is proposed to quantify the transport of ozone - or any other atmospheric constituent - by objectively-defined air-masses. In the framework of mesoscale modelling, this method is an alternative to classical Eulerian or trajectorybased methods, which suffer from many drawbacks at this scale. The elementary air-parcels are tagged with their initial location (what is made possible in the model by passive transport of three tracer fields initialized with the space coordinates). This enables to retrieve not only their back-trajectories but also their physical and chemical history. This information is in turn used to relevantly define transporting air-masses along objective criteria. For instance the ozone mass that has left the planetary boundary layer (PBL) to intrude the free troposphere (FT) in a given time interval, is carried by the ensemble of air-parcels that were initially in the PBL but are finally in the FT. Such an air-mass can be characterized by e.g., a criterion on the initial and final values of the turbulent kinetic energy of the air-parcels. The last step to obtain the sought ozone 15 mass is a simple spatial integration of the ozone concentration over the so-defined air-mass. Two case-studies are presented as illustrations with increasing complexity: (i) the downward transport of ozone accompanying a tropopause fold, across a midtropospheric altitude level; (ii) a case of PBL-to-FT transport, as evoked above.

\section{Introduction}

20 Tropospheric ozone is not only a major atmospheric photo-oxidant but also the third most active greenhouse gas after carbon dioxide and methane (IPCC, 2001). Its radiative impact is maximum in the upper troposphere (de Forsters and Shine, 1997) where it even equals that of the carbon dioxide (Micley et al., 1999). It is thus crucial to acquire a quantitative and comprehensive knowledge of the terms of its budget in order
ACPD

4, 8103-8139, 2004

\section{Quantification of mesoscale transport}

F. Gheusi et al.

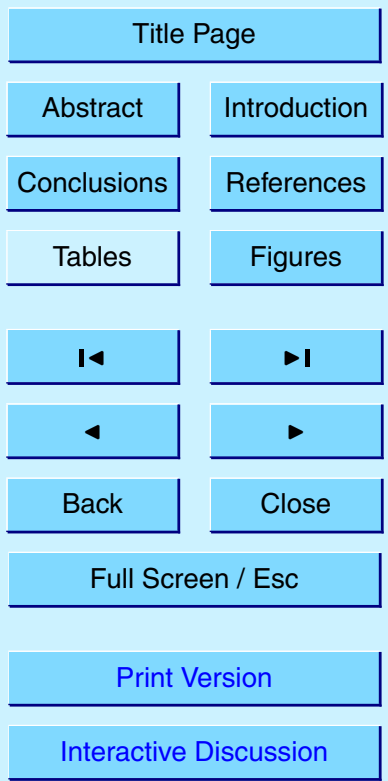

EGU 
This budget of tropospheric ozone still remains quantitatively very uncertain and difficult to establish due to its high photochemical reactivity and the fact that this gas is not directly released in the atmosphere but produced in-situ by chemical cycles including various precursor species as organic compounds, nitrogen oxides, etc. Especially at 5 the global scale with up-to-date chemistry-transport numerical models (CTMs) there is still a great dispersion of the terms of stratospheric ozone influx into the troposphere and surface deposition. That dispersion appears to be "sponged" by the modelled chemical cycles. As a result the simulated photochemical net production turns out to be either positive or negative according to various models (IPCC, 2001).

10 Contributing especially to the complexity of the problem, it is established that the kinetic regimes of chemical ozone production/loss in the planetary boundary layer (thereafter PBL) and free troposphere (thereafter FT) are very different due to contrasting dilutions of precursors and non-linear sensitivity on their concentrations. CTMs poorly capture this difference and this problem will persist as long as ozone exchanges 15 through the boundaries of the PBL and FT are not correctly represented in the models - even with the best possible chemical scheme.

More specifically the question of free-tropospheric ozone has become in the last years a major concern in the scientific community. The background ozone concentration has notably increased whereas the urban precursor emissions and local ozone pollution peaks have decreased past the last decade in the developed countries. Thus the problem of ozone pollution is shifting from a local to a global issue. In particular long-range transport and slow ozone production in the free troposphere are now recognized to take an important part in regional budgets (e.g., Chattfield et al., 2004; Sauvage et al., 2004).

As the ozone budget of the free troposphere is significantly controlled by exchange processes at its upper and bottom boundaries, one has to be able to assess these exchanges precisely. A difficulty is that most of these exchange processes occur at scales meso- $\alpha,-\beta$ or even finer. Another major difficulty is that the crossed dynamical boundaries - the tropopause and the PBL top - are highly deformable and unstationary,
ACPD

4, 8103-8139, 2004

\section{Quantification of mesoscale transport}

F. Gheusi et al.

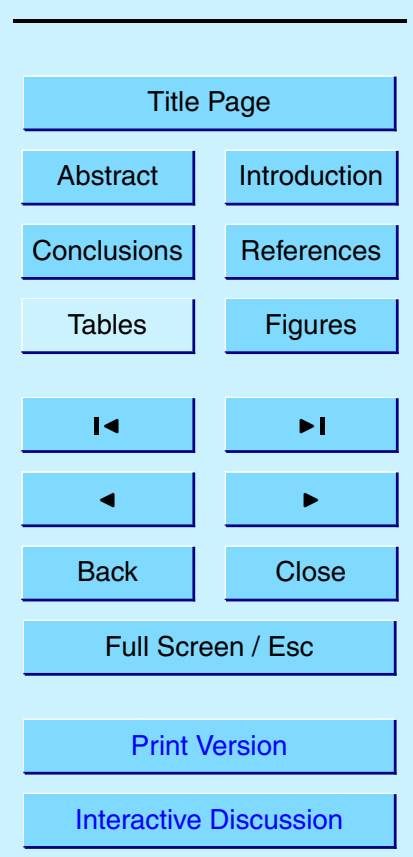

EGU 
and are not defined by a geometrical but physical criterion - for instance on potential vorticity (PV) and turbulent kinetic energy (TKE), respectively.

Although not impossible it is uneasy to express mass fluxes across such complex surfaces in the form of a diagnostic formula based on the Eulerian flow variables. Wei 5 (1987) proposed a formula for flux estimate across the tropopause based on the continuity equation. This formula (see Kowol-Santen et al., 2000, Eq. 2), takes into account the vertical velocity at the tropopause, the local vertical change of the tropopause position and the isentropic transport across the tropopause. A simple form is attained only if PV is taken as vertical coordinate (see Kowol-Santen et al., 2000, Eq. 3). This 10 however requires everywhere a one-to-one correspondence between PV and altitude, which is in general not the case in mesoscale modelling - of a tropopause fold for instance. The flux fields derived from the formula in its general form suffer from smallscale noise due to horizontal spatial derivatives (Wirth and Egger, 1999) all the more as the model horizontal resolution is fine.

15 Thus in the recent years most quantitative studies on stratosphere-troposphere exchanges (thereafter STE) preferred Lagrangian approaches using various techniques. The most common is based on the computation of large gridded ensembles of trajectories, with automatic selection of those corresponding to pre-defined STE events. The exchange assessment (in terms of mass of dry air, ozone, etc.) relies on the assump20 tion that each parcel transport a fixed (finite) mass or volume of air - that of a grid-cell. As trajectories can be computed from pre-existing global meteorological analyses, this technique has been used to establish climatologies of STE events and accompanying mass fluxes at the hemispheric scale (e.g., Sprenger and Wernli, 2003; Stohl et al., 2003). However Gheusi and Stein (2002) pointed out limitations of trajectory-based analyses (in particular resulting from time and space interpolations of coarse wind fields, and the absence of sub-grid transport parametrization in the trajectory computation) and stressed that these limitations can be critical for studies at mesoscale. Moreover Stohl et al. (2004) recently warned on the dynamical inconsistency of subsequent analysed wind-fields as a source of exchange overestimation.
ACPD

4, 8103-8139, 2004

\section{Quantification of mesoscale transport}

F. Gheusi et al.

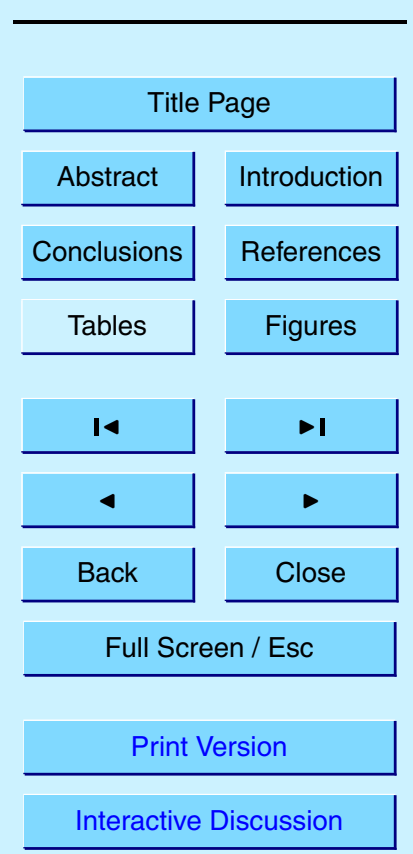

EGU 
The isentropic and quasi-horizontal stretch and cut-off of stratospheric PV-filaments from high to sub-tropical latitudes has been identified as a major process of ST exchange. Even if such filaments often extend over thousands kilometres, they can be as thin as few tens kilometres due to intense stretching in baroclinic wave developments 5 at mid-latitudes. Based on the assumption of PV conservation in adiabatic inviscid flows, the technique of PV-contour advection on isentropic surfaces allows to generate small-scale features from initially coarse PV fields from meteorological analyses and to simulate the evolution of stratospheric filaments with some realism. Dethof et al. (2000) proposed an algorithm based on this technique to calculate mass budgets across the 10 tropopause. A "surgery" routine is used to remove small-scale structures by merging or disconnecting contours if they get closer than a specified cutoff scale. Stratospheric intrusions are thus allowed to cut off from the polar stratospheric reservoir then a simple mass integration is finally performed to assess the accompanying stratosphere to troposphere exchange. The above method of cross-tropopause transport quantificaflow - not always fulfilled e.g., in extra-tropical cyclones that are the most favourable conditions for ST transports.

Although the above Lagrangian methods to asses ST exchanges are quite different in their details, they can all be outlined along a single two-step process:

1. Identification of coherent air-masses (stratospheric filaments, tropopause folds, cumulonimbus overshoots, etc.) that (more or less irreversibly) intrude into, or extrude from, the troposphere;

2. Quantification of the mass of dry air, ozone, or any other atmospheric constituent, transported by these air-masses.

25 It should be noted that the same two-step process can be followed to quantify transports from the planetary boundary layer into the free troposphere - or conversely.

In the present paper a new method is proposed to assess the transport of atmospheric constituents - focusing on ozone as an example - across the boundaries of the 8107
ACPD

4, 8103-8139, 2004

\section{Quantification of mesoscale transport}

F. Gheusi et al.

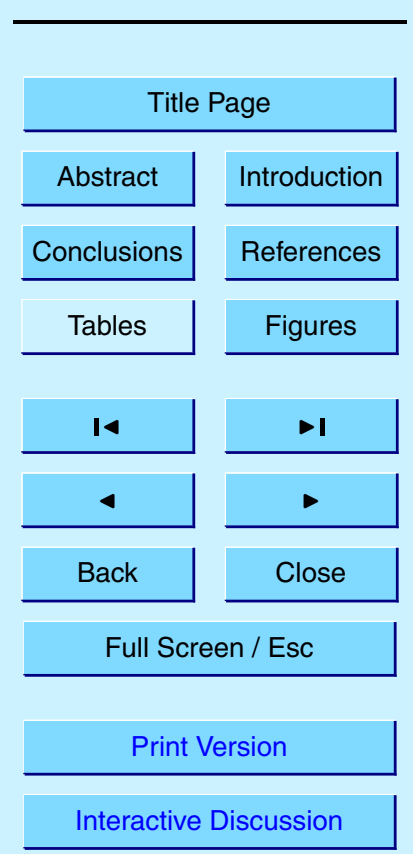

EGU 
free troposphere in the framework of numerical-model based studies at scales meso- $\alpha$, $-\beta$, or even below, where the limitations of the Lagrangian techniques mentioned above become critical.

Also following the above two-step process, the new method is based on the tech5 nique of Lagrangian analysis using Eulerian passive tracers developed by Gheusi and Stein (2002). Its use does not require any constraining assumption (such as adiabatic or inviscid flow, PV conservation, etc.) and has proven its efficiency to identify, track and study meso $\beta$-scale coherent air-masses in complex situations (e.g., Gheusi and Stein, 2002; Asencio et al., 2003; Cousin et al., 2004).

10 Thus this Lagrangian technique appears to be of immediate applicability for step 1 of the quantification process when considering transports by mesoscale air-masses into or from the free troposphere. So the main objective of the paper is to define a procedure for step 2. Two examples of increasing complexity will be given to show how to quantify ozone transports into the free troposphere by a tropopause fold and a boundary-layer plume, respectively.

The remainder of the paper is structured as follows. In Sect. 2 the model specifications will be briefly given. Some aspects of the Lagrangian analysis technique of Gheusi and Stein (2002) will be also recalled, that are essential to understand the whole transport quantification process. In Sect. 3 the method will be carried out in a simple configuration to assess a descending time-integrated ozone flux associated to a tropopause fold across a fixed altitude level. In Sect. 4 a more complex situation of $\mathrm{BL}$ ozone plume is considered where the crossed surface is the PBL top defined with a given value of the turbulent kinetic energy. Some aspects of the method (errors, calibration, advantages) are discussed in Sect. 5. Conclusions are given in Sect. 6.
ACPD

4, 8103-8139, 2004

\section{Quantification of mesoscale transport}

F. Gheusi et al.

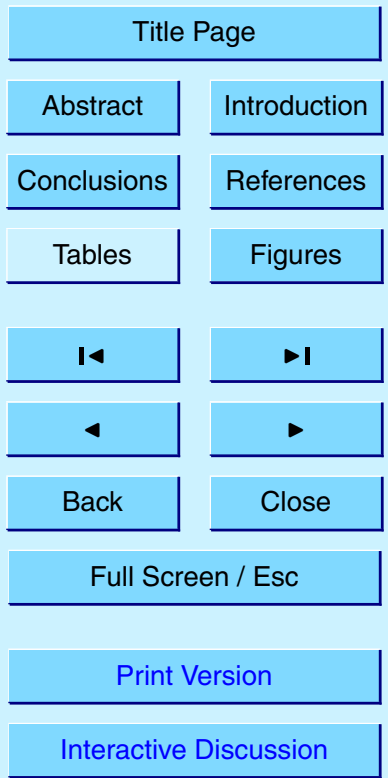

EGU 


\section{Model specifications and Lagrangian technique}

\subsection{Model specifications}

The numerical simulations are performed with $\mathrm{MesoNH}$ - a non-hydrostatic anelastic mesoscale model jointly developed by the Laboratoire d'Aérologie (Toulouse, France)

5 and the CNRM (Météo-France). The configurations of MesoNH used in Sects. 3 and 4 differ in terms of model domain, resolution, microphysics and ozone chemistry. Specific details will be introduced in the respective sections. The main common features are given below.

The dynamical core of the model is described in Lafore et al. (1998). A terrain10 following vertical coordinate is used to include orography, based on altitude levels and the Gal-Chen and Sommerville (1975) transformation. Subgrid turbulence is parametrized with a 1-D, 1.5-order scheme using the turbulent kinetic energy as prognostic value (Cuxart et al., 2000) and the Bougeault and Lacarrère (1989) verticalmixing length.

15 The warm-cloud microphysics scheme is of Kessler (1969) type including water vapour and liquid water in the form of non-precipitating cloud droplets or rain. Subgrid convection is parametrized with a 1-D massflux scheme (Bechtold et al., 2001). The surface scheme is "Interactions between the Soil, Biosphere and Atmosphere" (ISBA, Noilhan and Planton, 1989). The radiation scheme is described in Morcrette (1991).

A complete set of references and comprehensive documentations can be found on the official MesoNH web site (http://www.aero.obs-mip.fr/mesonh/).

Initialization and coupling at the model boundaries for the meteorological fields is realized from French operational analyses ARPEGE (Thépaut and Coauthors, 1998).

25 The model also include mixing ratios of chemical species that are either treated as passive tracers (Sect. 3) or evolve according to a chemical scheme (Sect. 4). In both cases chemical mixing-ratio fields for initialization and coupling result from the CTM at
ACPD

4, 8103-8139, 2004

Quantification of mesoscale transport

F. Gheusi et al.

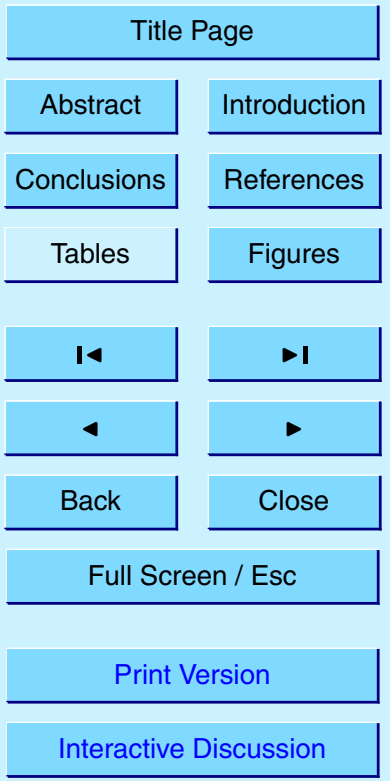

EGU 
The Lagrangian technique used in this paper is here only briefly recalled. Full details and discussions can be found in Gheusi and Stein (2002) and Gheusi and Stein (2004, 5 personal communication ${ }^{1}$ ).

The Lagrangian description of a flow consists in specifying for each elementary fluid parcel (hereafter referred to as a Lagrangian parcel), and at any time, its location as well as any quantities (velocity, pressure, temperature, chemical species concentrations, etc.) characterizing the parcel properties. This requires that each Lagrangian parcel has to be labelled so that its identity remains unambiguous. A possible way is to label each parcel with its location, say $x_{0}$, at an arbitrary reference time $t_{0}$.

Like most fluid-dynamics numerical models, MesoNH is formulated with differential equations operating on Eulerian fields. In this framework it is in fact very easy to make such a labelling, based on the transport of passive scalar variables - a very common task in numerical modelling. The method consists, at an arbitrary reference time $t_{0}$, in initializing three fields of passive scalars with the three space coordinates, namely:

$x_{0}\left(x, t_{0}\right)=x$,

$y_{0}\left(x, t_{0}\right)=y$,

$z_{0}\left(x, t_{0}\right)=z$.

20 Since these fields (hereafter referred to as the "initial coordinates") are passive scalars driven by the flow, their evolution is governed by the advection equation

$\frac{\partial x_{0}}{\partial t}=-\boldsymbol{u} \cdot \nabla x_{0}$

where $\boldsymbol{u}$ is the velocity field and $\boldsymbol{x}_{0}(\boldsymbol{x}, t)$ is the vector field formed with the components $x_{0}, y_{0}, z_{0}$. The discretization of Eq. (1) in finite elements implies that the three

\section{Quantification of mesoscale transport}

F. Gheusi et al.

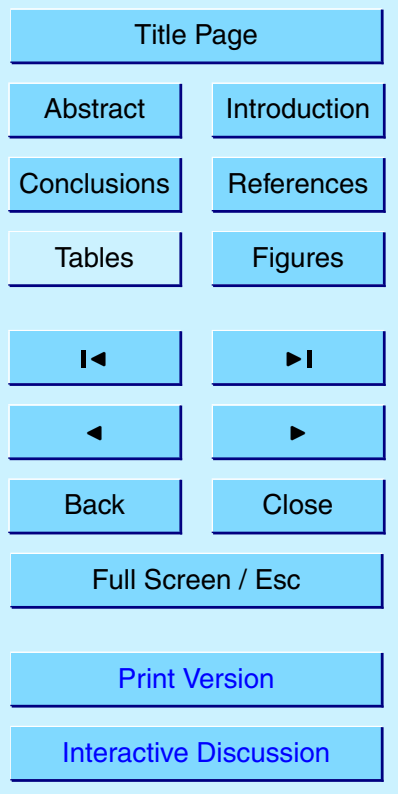

EGU

${ }^{1}$ http://www.aero.obs-mip.fr/mesonh/dir_doc/lag_m45_21mai2004/lagrangian_m45/ 
passive-tracer fields experience not only advection but also the sub-grid turbulent and convective transports through the corresponding parametrizations.

It should be remarked that conservation of the initial coordinates is assumed by definition and is free of constraining hypotheses (like adiabatic or inviscid flow, PV 5 conservation, etc.) so that this Lagrangian technique can be used in the most complex meteorological situations at mesoscale.

Thus at any time $t>t_{0}, x_{0}(x, t)$ provides the location at time origin $t_{0}$ of the air-parcel that is now at location $\boldsymbol{x}$. This is immediately useful for studying mesoscale exchanges since air-masses intruding from an atmospheric reservoir to another appear on initial 10 coordinate fields as coherent ensembles with a common geographical origin.

Another straightforward consequence is that for instance the initial potential vorticity $P V_{0}$ (or any other quantity) that the considered Lagrangian parcel had at time origin $t_{0}$ can be simply known by reading the (Eulerian) $P V$ field at time $t_{0}$ and location $x_{0}$ : $P V_{0}=P V\left(x_{0}, t_{0}\right)$, or in the fully developed Eulerian form

${ }_{15} P V_{0}(x, t)=P V\left(x_{0}(x, t), t_{0}\right)$.

This will be useful to discriminate air-parcels originating from reservoirs defined along physical criteria. For example, if the stratosphere is defined at time $t_{0}$ as the region with $P V>2 \mathrm{PVU}$, at time $t>t_{0}$ any air-parcel in the troposphere with $P V_{0}>2 \mathrm{PVU}$ is immediately identified as a parcel originating from the stratosphere ${ }^{2}$.

\section{Transport across a fixed horizontal surface}

In this section we consider a case of ozone import in the troposphere by a tropopause fold that is known to be among the main processes that contribute to the global de-

\footnotetext{
${ }^{2}$ This technique is close to the "Reverse Domain Filling" (RDF, e.g., Schoeberl and Newman, 1995). However the reconstructed potential vorticity field $P V_{0}$ is here not obtained by means of an ensemble of backtrajectories but the reconstruction is based on the initial location (Eulerian) field $x_{0}(x, t)$.
}

ACPD

4, 8103-8139, 2004

\section{Quantification of mesoscale transport}

F. Gheusi et al.

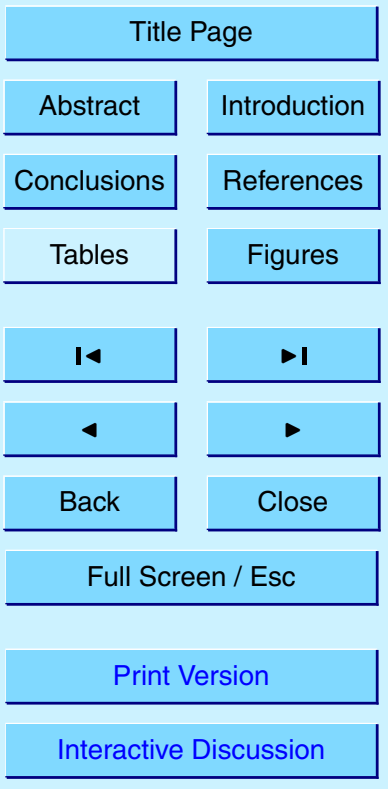

EGU 
scending stratospheric ozone flux at extra-tropical latitudes.

The fold was present on 10 February 2002 over western Europe and was detected by a commercial aircraft A340 instrumented with MOZAIC sensors (Nédélec et al., 2003) that took off from Frankfurt (Germany) on the same day. It is well visible in ozone $5\left(\mathrm{O}_{3}\right)$, carbon monoxide ( $\left.\mathrm{CO}\right)$ and humidity vertical profiles (Fig. 1) as an $\mathrm{O}_{3}$-rich, COpoor and dry thin layer between altitudes of 4 and $5 \mathrm{~km}$. The fold accompanied the development of a classical extra-tropical baroclinic-wave over eastern Atlantic.

\subsection{Tropopause fold simulation and validation}

The considered case of winter extra-tropical wave development necessitates that the model microphysics also includes three iced-phase species (non-precipitating cloud particles, snow flakes and graupels) following the "Ice3" scheme (Pinty and Jabouille, 1998).

The life-time of ozone in the upper troposphere in winter at mid and high latitudes is estimated to several weeks (von Kuhlmann et al., 2003). The simulation presented in this section runs over $48 \mathrm{~h}$ so that chemical reactions including ozone have been neglected and that gaseous constituent is treated in the model as a passive tracer.

The model domain extends over $3000 \mathrm{~km}$ meridionally and $4500 \mathrm{~km}$ zonally in polar strereographic projection, and covers eastern Atlantic and western Europe with a horizontal resolution of $30 \mathrm{~km}$. The model has 82 vertical levels with $40 \mathrm{~m}$ of resolution near constant up to the model top at $20000 \mathrm{~m}$.

The model was initialized on 9 February 2002 00:00 UTC. Figure 2 shows the altitude of the 1.5 PVU PV-isopleth on 9 February at 18:00 UTC and 10 February at 12:00 UTC. On this surface the baroclinic wave appears as a deep $(2000 \mathrm{~m}$ at least) V-shaped trough moving rapidly eastward while elongating southward and narrowing.

In case of multiple occurrence of the 1.5 PVU value on a given vertical, only the highest point of the PV-isopleth is represented in Fig. 2. This is the case in panel (b) near the western edge of the trough where tropopause folding has occurred - visible
ACPD

4, 8103-8139, 2004

\section{Quantification of mesoscale transport}

F. Gheusi et al.

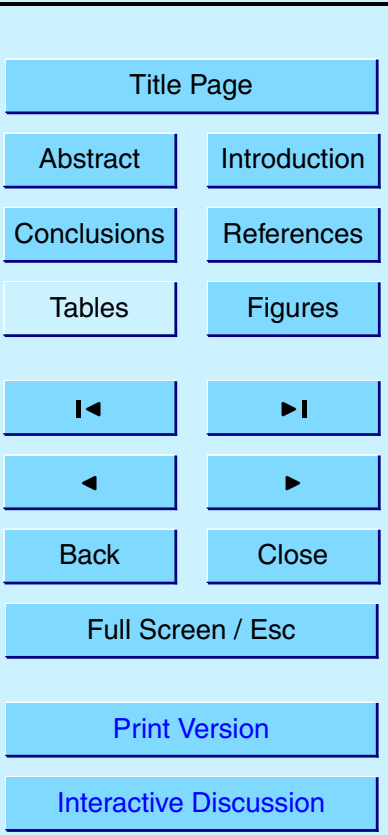

EGU 
as a discontinuity of the surface altitude (sudden drop from $10000 \mathrm{~m}$ down to below $7000 \mathrm{~m}$ ) just east of Frankfurt.

The vertical structure of the modelled fold in $\mathrm{PV}$ and $\mathrm{O}_{3}$ mixing-ratio not far NW of Frankfurt is shown in Fig. 3a. Airborne $\mathrm{O}_{3}$ measurements have also been emulated in 5 the model along the path of the MOZAIC aircraft. The real and simulated records are plotted together in Fig. 3b. In the model two ozone-rich layers (marked 1 and 2) are intercepted by the ascending aircraft (Fig. 3a) with their corresponding $\mathrm{O}_{3}$ peaks well visible in the simulated record (red curve in Fig. $3 b$ ).

The $\mathrm{O}_{3}$ layer 1 is associated to the tropopause fold (as shown by the coincidence 10 with the overturned PV-contour). Compared to the measurements (green curve in Fig. $3 b$ ) it is captured by the model at the right altitude and with satisfying amplitude and thickness (given the coarser vertical resolution of the model, $300 \mathrm{~m}$, with respect to that of the measurements, about $30 \mathrm{~m}$ ). In contrast the simulated feature 2 was not actually measured by the aircraft and there is also an underestimation of $\mathrm{O}_{3}$ concentration below $4000 \mathrm{~m}$. Nevertheless only the ozone intrusion due to the fold is under consideration in this study and the present simulation appears to be satisfying for the goal of quantifying the accompanyning transport of $\mathrm{O}_{3}$.

\subsection{Downward transport quantification}

The purpose in this subsection is to quantify the transport of ozone specifically as20 sociated to the tropopause folding process and accompanying subsident air motion. Precisely we seek to asses the mass of $\mathrm{O}_{3}$ (in $\mathrm{kg}$ ) crossing downward a reference altitude level, $z=4500 \mathrm{~m}$, during a given time period starting (arbitrarily) on 9 February 18:00 UTC. This mass therefore corresponds to a time-integrated mass-flux of $\mathrm{O}_{3}$ through that level. The reference altitude is chosen sufficiently low in the troposphere 25 to consider that this deep intrusion of stratospheric ozone is irreversible.

The process for that quantification has two stages: (i) to select objectively the ozonecarrying air-mass that has crossed downward the reference level during the $18 \mathrm{~h}$ period from 9 February 18:00 UTC to 10 February 12:00 UTC; (ii) to perform a volume inte-
ACPD

4, 8103-8139, 2004

\section{Quantification of mesoscale transport}

F. Gheusi et al.

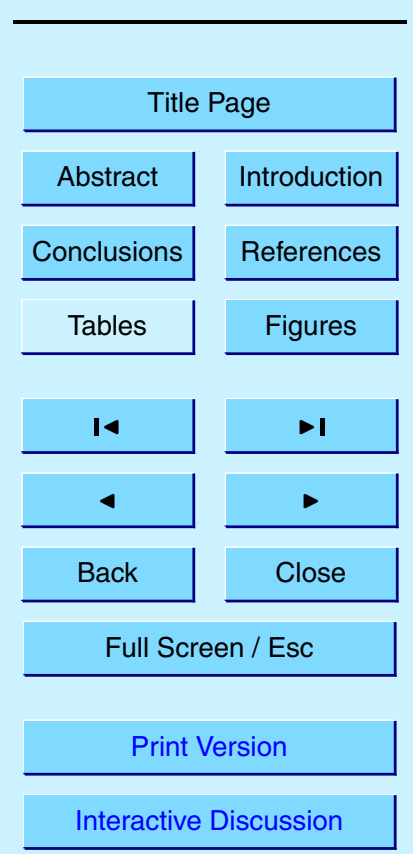

EGU 


\subsubsection{Air-mass selection}

4, 8103-8139, 2004

The first stage is based on the tracer field of initial altitude, $z_{0}(x, t)$ (see Sect. 2.2). Isopleths of this field correspond to surfaces that are initially horizontal at the time5 origin, then materially deformed by the flow. Such a surface is represented seen from above in Fig. $4 \mathrm{a}$. This shows the actual altitude after $18 \mathrm{~h}$, of the points of the surface that were initially at $4500 \mathrm{~m}$. This plot evidences the subsiding motion of air-parcels accompanying the tropopause folding process, down to altitudes as low as $3600 \mathrm{~m}$ (NS-oriented band in the blue-purple range, extending from north-eastern France to the North Sea). A vertical section (Fig. 4b) further illustrates the downward deformation of the material surface (visible as a contour) in the region of the ozone intrusion (and even shows that the $z_{0}$-surface itself has folded). Thus the $z_{0}$ field allows to outline vertical displacements integrated over the chosen time period.

This can serve to select objectively a descending air-mass as follows. Clearly all the air-parcels that were initially above $4500 \mathrm{~m}$ and are now below, have crossed downward the altitude level $4500 \mathrm{~m}$. It is in fact very easy to formulate this criterion by means of the initial altitude field, which is fulfilled for any air-parcel present at time $t$ at location $x=(x, y, z)$ if, and only if,

$z \leq 4500 \mathrm{~m}$.AND. $z_{0}(x, \mathrm{t}) \geq 4500 \mathrm{~m}$.

20 In Fig. 4b this statement is true for the whole air-mass located below $4500 \mathrm{~m}$ but above the $z_{0}=4500 \mathrm{~m}$ isocontour (hatched area).

Finally we further restrict the selected descending air-mass within an arbitrary geographical domain represented in Fig. 5a, in order to filter any downward transport in the model domain not associated to the tropopause fold.

\section{Quantification of mesoscale transport}

F. Gheusi et al.

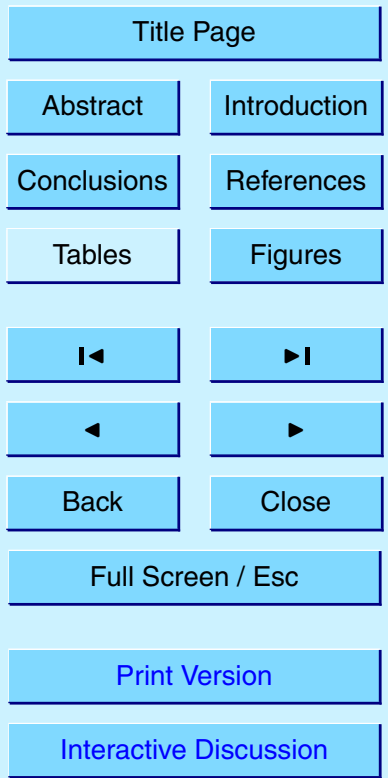

EGU 


\subsubsection{Mass integration}

Figure 5 shows a field equal to the $\mathrm{O}_{3}$ mixing-ratio field where the above criterion (3) is fulfilled, and zero elsewhere. This three-dimensional field (noted $\left[\mathrm{O}_{3}\right]_{\downarrow}$ ) hence represents the ozone distribution restricted to that transported downward through the $54500 \mathrm{~m}$ altitude level since the time origin. It is now straightforward to assess the total ozone mass contained in the selected air-mass by simple integration over space:

$\iiint\left[\mathrm{O}_{3}\right]_{\downarrow} \frac{M_{\mathrm{O}_{3}}}{M_{\text {air }}} \rho_{\text {air }} \mathrm{d} \mathcal{V}$,

where $M_{\mathrm{O}_{3}}$ and $M_{\text {air }}$ are the molar mass of ozone and air (48 and $29 \mathrm{~g} / \mathrm{mol}$, respectively), $\rho_{\text {air }}$ the density of air and $\mathrm{d} \mathcal{V}$ a volume element.

The discretized calculation from the model fields is performed as follows. The above criterion is tested at each model grid-point, producing a three-dimensional binary array where the $0 / 1$ (false/true) transition surface is a pixelized contour encompassing the selected air-volume. This contour is smoothed by application in each direction of space, of a running-mean operator with weight $\frac{1}{2}$ for the local grid point and $\frac{1}{4}$ for the two adjacent points. As a result the transition region appears as "grey" values (i.e., continuously between 0 and 1). Finally only the model cells where this truth-indicator equals or exceeds the threshold $\alpha=0.57$ are kept as finite volume-elements for the integration ${ }^{3}$.

In the considered example this yields a mass of ozone of $19.410^{6} \mathrm{~kg}$ in $18 \mathrm{~h}$ for 20 this single ozone intrusion event. Estimations given in the literature for daily ozone quantities transported across the tropopause into the troposphere by single tropopause events were gathered by Beekmann et al. (1997). Those range between 1.8 and 10.4 $10^{32}$ molecules per day (molec/d). The mass found above for an $18 \mathrm{~h}$ period corresponds to a mean rate of $3.310^{32} \mathrm{molec} / \mathrm{d}$, well within that range of values.

\footnotetext{
${ }^{3}$ The calibration of the $\alpha$ parameter is described in Sect. 5.2.
}

ACPD

4, 8103-8139, 2004

\section{Quantification of mesoscale transport}

F. Gheusi et al.

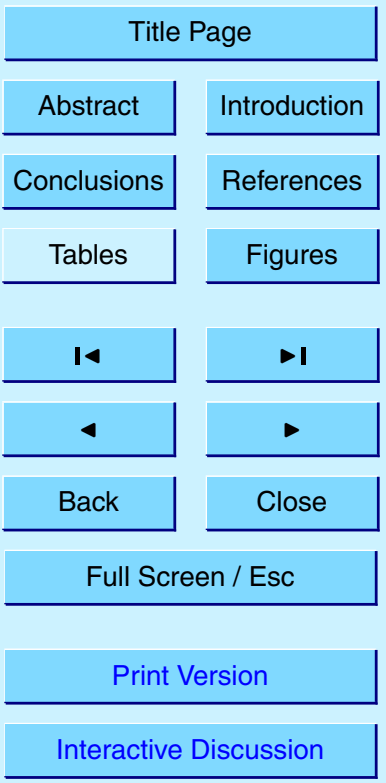

EGU 
It is noteworthy that the latter downward flux across the $4500 \mathrm{~m}$ altitude level is found to have the same order of magnitude as those estimated across the tropopause. This illustrates that tropopause folds should be considered as deep and bursty injections of ozone into the troposphere, and thus points out a severe limitation of flux-type for5 mulations at the tropopause level for the tropospheric forcing in large-scale long-range models of tropospheric ozone. Further discussion on that topic is however beyond the goals of the present study.

Regarding the method itself, its advantages in a so basic case - a flux through a horizontal fixed surface - compared to a classical on-line Eulerian method will be 10 discussed in Sect. 5 but before a much less trivial case is presented in the following section.

\section{Transport across an unstationary complex surface}

As stressed in Sect. 1, it may be uneasy to express mass fluxes across complex unstationary surfaces, based on the Eulerian flow variables, so that Lagrangian methods 15 are often preferred. This is the case here where the considered surface is the top of the boundary layer, defined by a threshold value on the turbulent kinetic energy (TKE). The chosen meteorological situation is a summer sunny day on the Mediterranean coast where a marked diurnal cycle and the development of coastal breezes render the boundary layer particularly unstationary and complex.

\subsection{Model configuration and meteorological situation}

The model configuration was designed for the study of summer ozone-pollution episodes in the boundary layer in the region of Marseille during the ESCOMPTE campaign in 2001 (Cousin et al., 2004). The $720 \mathrm{~km} \times 720 \mathrm{~km}$ model domain is centred over the north-western Mediterranean basin (Gulf of Lion) and includes part of the French
ACPD

4, 8103-8139, 2004

Quantification of mesoscale transport

F. Gheusi et al.

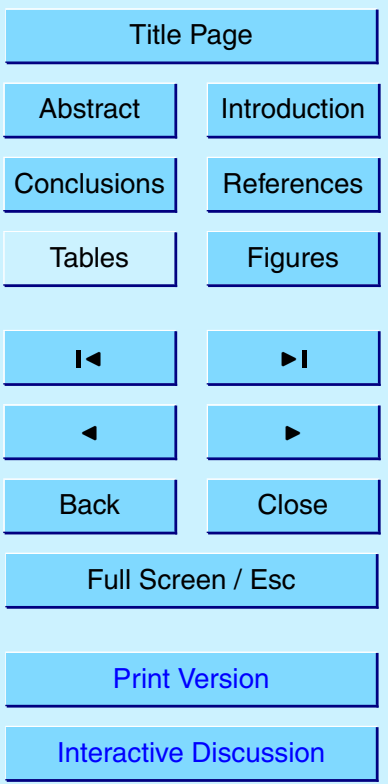

EGU 
Central and southwestern Alps) with a horizontal resolution of $9 \mathrm{~km}$. The model has 54 vertical levels with $10 \mathrm{~m}$ of resolution near the ground progressively stretched to $1500 \mathrm{~m}$ at $10000 \mathrm{~m}$. Above this altitude it remains constant up to the model top at $15000 \mathrm{~m}$. The chemical evolution of ozone mixing-ratio is taken into account through 5 the chemistry module ReLACS (Crassier et al., 2000; Tulet et al., 2003) derived from RACM (Stockwell et al., 1997). ReLACS operates on 128 chemical reactions involving 37 gaseous species, and is coupled on-line with Meso-NH. More details on the specific design of the model for the ESCOMPTE campaign are provided by Cousin et al. (2004).

10 The situation considered here is the afternoon of 23 June 2001. A high-pressure regime was well established over the Gulf of Lion and nearby, with sunny weather and a gentle WNW'ly synoptic flux (of about $15 \mathrm{~m} / \mathrm{s}$ ) in the mid-troposphere (Fig. 6a). Such conditions dominated by radiation were very favourable to the development in the afternoon of mountain- and sea-breeze in the lowest levels (below 200 ma.s.l.) all along the coast of the Gulf of Lion (see Figs. 6b and 9a). A deep boundary layer (exceeding $2000 \mathrm{~m}$ ) has formed above the relief, and especially along the convergence line delimiting the penetration of the breeze inland (Fig. 6b and 9a). It is fully developed around 15:00 UTC then rapidly collapses after 17:00 UTC (in the same time as the breeze circulation).

The ozone mixing-ratio field together with a marker of the boundary layer - defined as $T K E \geq 0.2 \mathrm{~m}^{2} / \mathrm{s}^{2}$ (about $10 \%$ of typical values for a well-developed boundary layer) - are displayed at $z=2000 \mathrm{~m}$ in Fig. 7 at the climax of the boundary layer development (15:00 UTC), then few hours later in the early evening (20:00 UTC). At 15:00 UTC ozone-laden air (mixing-ratio above $70 \mathrm{ppbv}$ ) is well correlated with the boundary layer where developed up to $2000 \mathrm{~m}$ or above. This distribution is clearly due to turbulent upward transport of ozone photochemically formed in polluted air at lower levels in the few past hours. At 20:00 UTC the boundary layer has almost everywhere collapsed below $2000 \mathrm{~m}$ but the ozone-rich air mass is still present at this altitude and has been transported over the Mediterranean over few tens kilometres by the north-westerly wind.
ACPD

4, 8103-8139, 2004

\section{Quantification of mesoscale transport}

F. Gheusi et al.

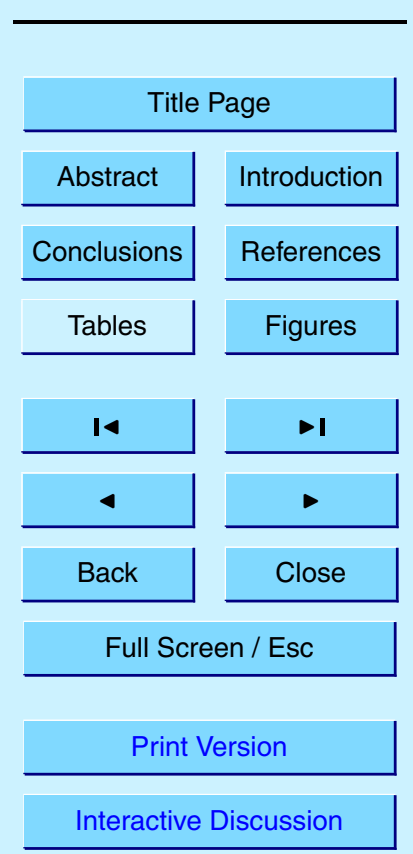

EGU 
The depicted situation illustrates how an ozone-rich air-mass can be formed in the boundary layer then be released into the free troposphere where it may then experience transport over a more or less long range. The next subsection is devoted to the quantification of this ozone transfer from the boundary layer to the free troposphere.

5 4.2. Transport quantification through the PBL-top up to the free troposphere

As in previous Sect. 3 the two-step process will be followed, with first an appropriate and objective selection of the transporting airmass, then the integration of the ozone amount over this airmass.

Our objective is to asses the total ozone mass that has crossed upward the top of 10 the boundary layer (hereafter PBL-top) since the reference time $t_{0}=15: 00$ UTC. Here we consider the PBL-top to be the surface defined at any instant by the threshold value $T K E=0.2 \mathrm{~m}^{2} / \mathrm{s}^{2}$.

\subsubsection{Air-mass selection}

Any air-parcel that has crossed the PBL-top since the time origin $t_{0}$ was in the PBL at $15 t_{0}$ and is now in the free troposphere. In other words its TKE was above $0.2 \mathrm{~m}^{2} / \mathrm{s}^{2}$ at $t_{0}$ and is now (time $t$ ) below. The transporting airmass is thus formed by the ensemble of air-parcels that fulfil this criterion.

Recalling Eq. (2) (Sect. 2.2), the air-parcel at current time $t$ and location $\boldsymbol{x}$ had at $t_{0}$ a turbulent kinetic energy

$20 T K E_{0}=T K E\left(x_{0}(x, t), t_{0}\right)$.

The transporting airmass is thus defined by the conditions:

$\operatorname{TKE}(\boldsymbol{x}, t) \leq 0.2 \mathrm{~m}^{2} / \mathrm{s}^{2}$

.AND.

$T K E_{0}(x, t) \geq 0.2 \mathrm{~m}^{2} / \mathrm{s}^{2}$
ACPD

4, 8103-8139, 2004

Quantification of mesoscale transport

F. Gheusi et al.

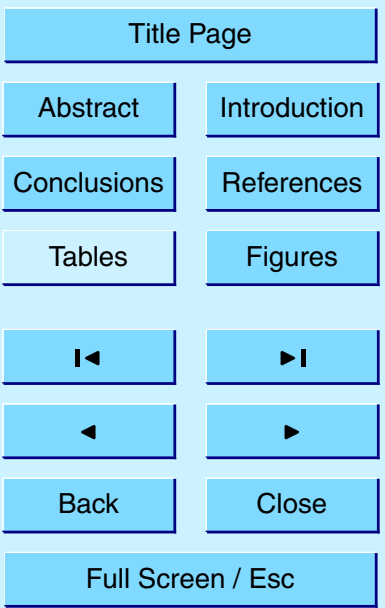

Print Version

Interactive Discussion

EGU 
It is also possible to further specify the definition of the airmass with an added geographical criterion, for example to restrict to air initially present over the southern Massif Central within the box drawn in Fig. 8a. The geographical added condition is thus:

$x_{\min } \leq x_{0}(\boldsymbol{x}, t) \leq x_{\max }$.AND. $y_{\min } \leq y_{0}(\boldsymbol{x}, t) \leq y_{\max }$,

5 (where $x_{\min }, x_{\max }, y_{\min }, y_{\max }$, are the coordinates specifying the box in Fig. 8a).

The airmass defined along the criteria of Eqs. (4), (5) and (6), is shown at several instants at $z=2000 \mathrm{~m}$ in Figs. $8 \mathrm{~b}-\mathrm{d}$, and in vertical section in Figs. 9b-d. More precisely the represented field is the "selected" ozone mixing-ratio (hereafter noted $\left[\mathrm{O}_{3}\right]_{\uparrow}$ ), obtained by multiplication of the mixing-ratio field by 1 where the above criteria are fulfilled, and by 0 elsewhere.

In these figures also appear the fields $T K E$ and $T K E_{0}$ used to define the airmass. The contour $T K E=0.2 \mathrm{~m}^{2} / \mathrm{s}^{2}$ is represented at the initial time $t_{0}$ (Fig. 8a) then the countour $T K E_{0}=0.2 \mathrm{~m}^{2} / \mathrm{s}^{2}$ at later instants, so that the south-eastward transport of the air parcels that initially formed the PBL-top is well visible over the Gulf of Lion (Fig. 8b-d). 15 Current values of TKE above $0.2 \mathrm{~m}^{2} / \mathrm{s}^{2}$ - i.e., parcels still in the $\mathrm{PBL}-$ are also indicated (hatched area). Therefore $\left[\mathrm{O}_{3}\right]_{\uparrow}$ appears to be non-zero inside the $T K E_{0}$ contour (parcels that were in the PBL) but outside the hatched area (parcels that are no more in the PBL).

\subsubsection{Mass integration}

20 Again a volume integral over the selected air-mass finally yields the expected result namely the total mass of ozone that originates from the box over the southern Massif Central and has crossed upward the PBL-top since the reference time $t_{0}$ :

$\iiint\left[\mathrm{O}_{3}\right]_{\uparrow} \frac{M_{\mathrm{O}_{3}}}{M_{\text {air }}} \rho_{\text {air }} \mathrm{d} \mathcal{V}$.
ACPD

4, 8103-8139, 2004

\section{Quantification of mesoscale transport}

F. Gheusi et al.

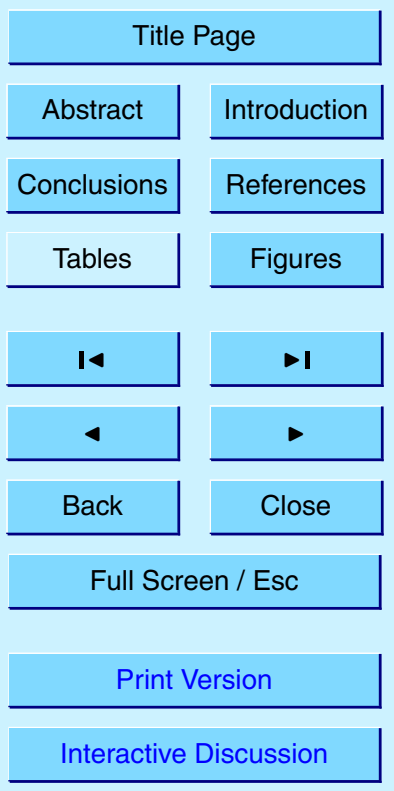

EGU 
In the same vein the total mass of air in the selected volume is:

$\iiint \delta_{\uparrow} \rho_{\text {air }} \mathrm{d} \mathcal{V}$

where $\delta_{\uparrow}$ is 1 in the selected volume and 0 elsewhere.

The numerical integration again follows the procedure described in Sect. 3.2.2.

5 The obtained ozone mass at 20:00 UTC amounts to $1.6010^{6} \mathrm{~kg}$, the air mass to $1.3610^{13} \mathrm{~kg}$.

These numbers mean little by themselves since the way to define the air-mass was arbitrary (chosen initial time, size and location of the initial box, etc.). More interestingly one could compare these amounts transferred to the free troposphere, to the respective 10 burdens initially present in the boundary layer within the box - thus assessing the efficiency of the transfer in the afternoon.

The latter burdens at initial time $t_{0}$ have been assessed by simple integration on model-cells with $T K E\left(x, t_{0}\right) \geq 0.2 \mathrm{~m}^{2} / \mathrm{s}^{2}$ (where of course $\boldsymbol{x}$ denotes any location within the box). The obtained burdens are $1.7310^{6} \mathrm{~kg}$ of ozone and $1.4410^{13} \mathrm{~kg}$ of air, that is an efficiency of about $95 \%$ for the transfer to the free troposphere. It is anyway reasonable to find such a large efficiency in the considered case, since comparison of the deepness of the boundary layer in Figs. 9a and d clearly shows that most of the boundary layer air at 15:00 UTC has been eventually transferred to the free troposphere at 20:00 UTC.

20 Whereas the mechanism of PBL to free troposphere transport described in the present case-study was also reported in previous studies (e.g., Millan et al., 1997), to our knowledge there is no corresponding estimation of the venting efficiency in the literature to compare to our result. Nevertheless breezes in mountain areas are known to be very efficient to transport PBL air to the free troposphere. For instance Henne et al. (2004) estimate that the PBL-air venting by breezes in a deep Alpine valley may amount to several times the volume of the valley itself in a day. The present case study illustrates that breezes at land-sea interface can also be very efficient to pump air from the PBL.
ACPD

4, 8103-8139, 2004

\section{Quantification of mesoscale transport}

F. Gheusi et al.

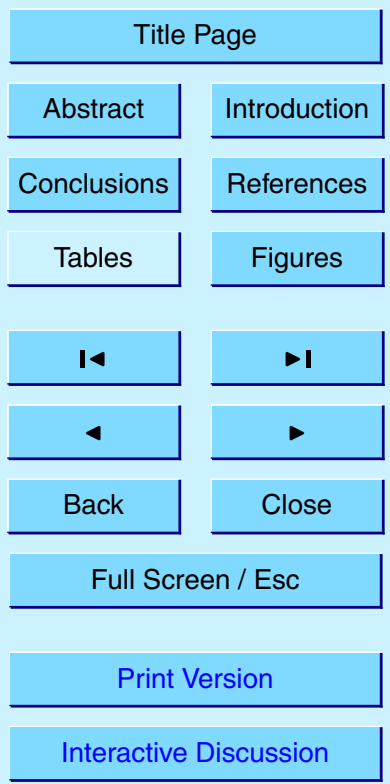

EGU 


\section{Discussion on the method}

\subsection{Errors}

As the proposed method relies on (i) the definition of an air-mass and (ii) an integration over this airmass, the uncertainty on the result ${ }^{4}$ comes from (i) the error on the location 5 of the air-mass boundary and (ii) errors from integration near this boundary due to the model discretization in finite elements.

Therefore the boundary region (the "grey" region mentioned in Sect. 3.2.2) appears to be critical. Thus it is useful to estimate, among $N$ model cells constituting the selected air-mass, what part of them $(\Delta N)$ are marginal cells. Assuming a compact 10 geometry for the air-mass (sphere or cube) one has

$$
\Delta N / N \sim 3 N^{-\frac{1}{3}}
$$

as an indicator of the relative error.

For instance in the investigated case of boundary layer plume (Sect. 4), conditions (4) (5) and (6) at 20:00 UTC are satisfied for 1797 model grid-cells so that $\Delta N / N \approx 25 \%$. 15 This is quite large but, beyond improvements that can be expected on both error causes mentioned above (air-mass definition and volume integration), a heuristic calibration based on a mass-conservation criterion is proposed to constrain the result in a much narrower range of uncertainty. This is explained in the next subsection but before the causes of error are further discussed.

20 Regarding first the numerical volume integrations, the scheme used for this preliminary study is very simple but likely far from the state of the art. Especially the way to integrate the marginal region of the air-mass is critical. Here the result depends on the chosen $\alpha$ threshold (introduced in Sect. 3.2.2) but this provides a potential of tuning that is exploited to calibrate the integration (see below Sect. 5.2).

\footnotetext{
${ }^{4}$ Beyond the uncertainty coming from the model Eulerian fields involved in the integral.
}

4, 8103-8139, 2004

\section{Quantification of mesoscale transport}

F. Gheusi et al.

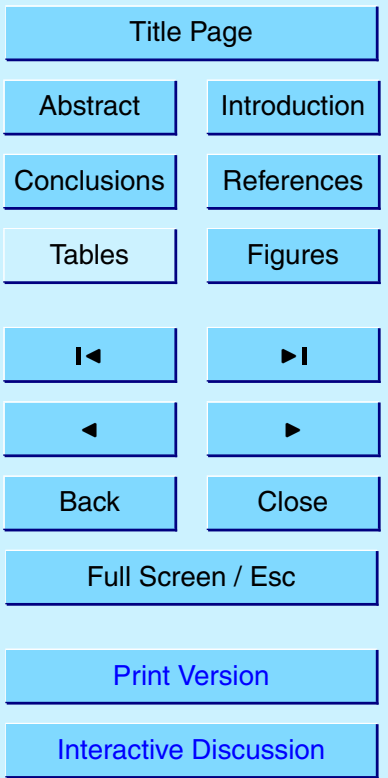

EGU 
Regarding the boundary of the selected air-mass, its location is critically linked to past ("initial") locations and physical parameters of air-parcels. The Lagrangian technique to retrieve them relies partly on spatial interpolations - that is known to be a source of error in Lagrangian techniques. These are simply linear in the current im5 plementation in MesoNH. However this Lagrangian problem is not unlike that considered in semi-Lagrangian advection schemes - for which high-performance interpolation schemes have been developed and carefully tested, with a particular concern on massconservation. Such a scheme should be well suited to our goals and its implementation should gain precision in the selection of the air-mass under interest.

10 Also beyond technical considerations, there is a fundamental reason indicating that the Lagrangian retrieval of past locations and parameters should lead to systematic overestimation of the selected air-mass. The retrieval is indeed based on the advectiondiffusion of initial coordinates forward in time. It has been shown (e.g., Issartel and Baverel, 2003) that the advection-diffusion problem is self-adjoint. This means that the uncertainty region around the initial location $\boldsymbol{x}_{0}(\boldsymbol{x}, t)$ of the parcel currently present at $(x, t)$ is equivalent to the scatter produced at $(x, t)$ by advection-diffusion of an ink droplet introduced at $\left(x_{0}, t_{0}\right)$. Therefore the selected air-mass - i.e., the ensemble of model cells that fulfil a condition based on $\boldsymbol{x}_{0}(\boldsymbol{x}, t)$ - should spuriously increase as time goes by, leading to some overestimation. This was indeed the case in our gross results

\subsection{Calibration}

The $\alpha$ threshold (see Sect. 3.2.2) was used to calibrate a correction based on a massconservation criterion applied in a simple conservative case.

First we assessed as reference value the mass of air contained at 15:00 UTC in 25 the box of Fig. 8a and in the PBL, that is with a TKE equal or above $0.2 \mathrm{~m}^{2} / \mathrm{s}^{2}$. The integration was made by simply summing the mass of all model cells of that air-mass.

Then we selected at 20:00 UTC the ensemble of parcels that were at 15:00 UTC in the reference box and PBL. (Note that this ensemble includes the airmass defined in
ACPD

4, 8103-8139, 2004

\section{Quantification of mesoscale transport}

F. Gheusi et al.

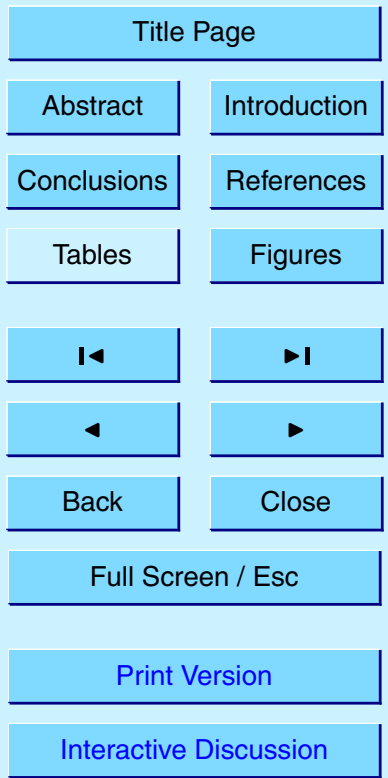

EGU 
Sect. 4.2.1 since for the former the conditions given by Eqs. 5 and 6 are used but not condition 4.) Evidently this ensemble should have at 20:00 UTC the same mass as initially. The best accordance - better that $3 \%$ - was obtained with $\alpha=0.57$.

This value has been retained for the whole study. However further work is needed 5 to asses the range of validity of this value, and the feasibility of an automatic casedependent calibration.

\subsection{Advantages}

In practice there are two steps for carrying out the method: first the systematic online calculation with the model of the three initial-coordinate tracers (Sect. 2.2); second

10 a scientific post-processing enabling the characterization of relevant air-masses and quantification of accompanying transports. Thus the method combines advantages of both steps.

On one hand on-line calculations have the benefit from the dynamical consistency and full temporal resolution of the model. In contrast off-line transport computations are known to suffer from temporal interpolation of wind-fields, and - when using series of analyses rather than model outputs - from the fact that the wind-fields at different times are not consistently linked to each other by the equations of fluid dynamics (Stohl et al., 2004).

On the other hand while the on-line calculation of the initial-coordinate tracers has 20 been performed in a "blind" systematic way (i.e., without any need to know a priori what happens or what is interesting in the modelled situation), the scientific work with the method is purely post-processing. This allows to fit at best the Lagrangian diagnoses to characterize relevant air-masses and quantify transport, without re-running the model.

We again underline here that despite the post-processing methodology, time25 integrated fluxes across surfaces (over $18 \mathrm{~h}$ in Sect. 3 and $5 \mathrm{~h}$ in Sect. 4) are obtained. Let us return for instance to the simple case considered in Sect. 3 - a downward flux through a horizontal fixed surface. With such a simple geometry a classical on-line flux integration from Eulerian fields of the model would be easy to formulate. How-

ACPD

4, 8103-8139, 2004

\section{Quantification of mesoscale transport}

F. Gheusi et al.

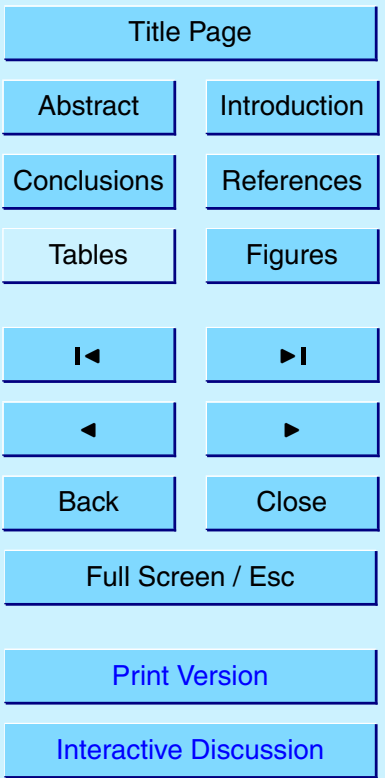

EGU 
ever the view to focus the flux calculation to the sole subsident motions accompanying the stratospheric intrusion would require to know at any time where and when the phenomenon is occurring. So the definition of an appropriately horizontally running window would be needed on the basis of a preliminary model-run to restrict the on5 line flux calculation to the intrusion under consideration. With our method in constrast, the time integrated vertical motions appear by themselves (Fig. 4) and the selection of the subsiding air-mass of interest (i.e., that accompanying the tropopause fold) is straightforward.

Thus the strategy of blind on-line calculation then intelligent low-cost post-processing 10

\section{Conclusions}

A new method is proposed to asses the quantity (i.e., mass) of ozone, air, or any atmospheric constituent, contained in transporting air-masses objectively defined by criteria on the geographical origin or physical evolution, of the air-parcels forming them. An appropriate choice of these criteria allows to asses time-integrated fluxes across

Lagrangian in nature but Eulerian in the formulation, based on the technique of initialcoordinate tracers developed by Gheusi and Stein (2002) that enables to retrieve the location or parameter value of any air-parcel at a prior instant.

Two illustrative case-studies have been presented. In the first one we assessed the 25 downward ozone-flux across a fixed mid-troposphere altitude level, accompanying a stratospheric ozone intrusion in a tropopause fold. The descending air-masses that has crossed the reference level during a chosen period of time, was simply identified

ACPD

4, 8103-8139, 2004

\section{Quantification of mesoscale transport}

F. Gheusi et al.

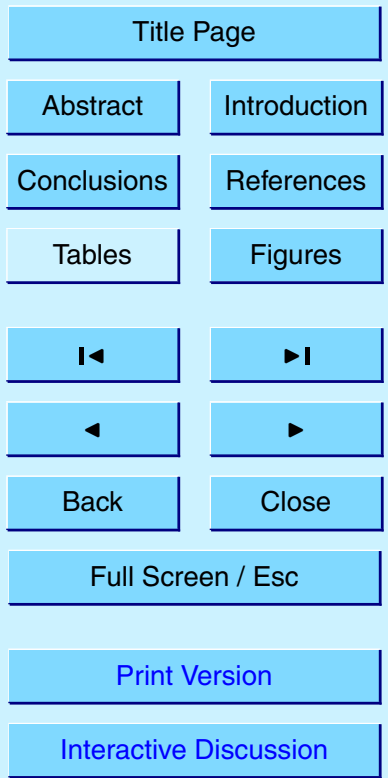

EGU 
as the ensemble of parcels that were above this level at the initial instant but below at the final instant. Then an spatial integration of the ozone concentration over this air-mass yielded the downward ozone-flux across the reference level integrated over the considered period.

5 As second example a boundary-layer plume intruding into the free troposphere was considered. The crossed surface was in this case complex and unstationary: the top of the boundary layer - defined with a fixed threshold value of the turbulent kinetic energy (TKE). Here the transporting air-mass was defined as the ensemble of parcels that were in the boundary layer (i.e., with TKE above the threshold) at the initial instant but 10 no longer (i.e., with TKE below the threshold) at the final instant. The corresponding time-integrated ozone-flux is again obtained by spatial integration over this air-mass.

The quantitative results found in each example are reasonable but we do not pursue any scientific discussion about them herein as the paper was focused on the method and the examples were chosen for their illustrative character. However, potential scientific applications of this new method are numerous and some are proposed here. Whereas in the second case study the venting of the boundary layer to the free troposphere was estimated, this method can reversely be used to quantify the entrainment from the free troposphere to the planetary boundary layer. This quantification is particularly important to understand the enhancement of ozone during the daytimes in the boundary layer. Another domain of application concerns the aerosol budget. The most likely site for nucleation to take place is generally the mixed layer of the entrainment zone, while the free troposphere can be excluded as nucleation region (Nilsson et al., 2001). The estimation of the two-way air-mass exchange between the boundary layer and the free troposphere is still to be done in order to precise where the triggering conditions for nucleation are fulfilled. Regarding the regional transport of pollution, a critical question is the relative importance of direct export of ozone to the free troposphere vs. ozone production due to exported nitrogen oxides and organic nitrates. This Lagrangian method is a promising tool to calculate the term of transport for ozone and its precursors, and consequently to assess the ozone photochemical sources and
ACPD

4, 8103-8139, 2004

\section{Quantification of mesoscale transport}

F. Gheusi et al.

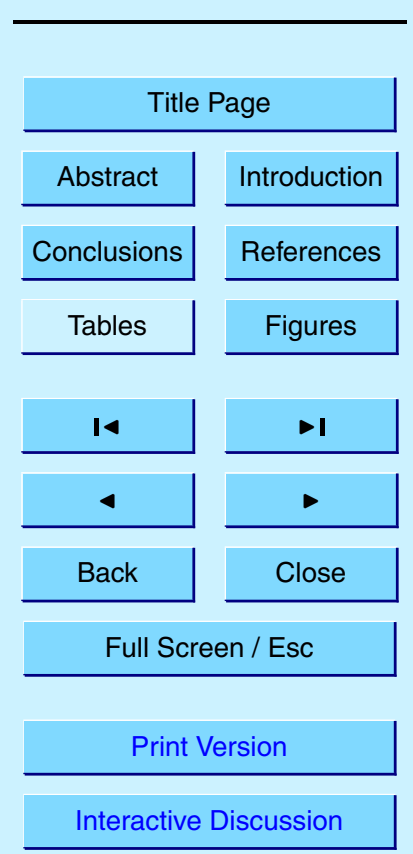

EGU 
sinks in the contoured air-masses.

Regarding the method itself, a calibration based on a mass-conservation argument enables to constrain the uncertainty on the air-mass integration within few percents of the result (besides the proper uncertainty on the integrated field from the model). Fur5 ther work is however needed to find an automatic procedure to make a case-dependent calibration. Improvements are also expected on the Lagrangian retrieval technique that serves to define the transporting air-mass (in particular regarding the interpolation scheme that should ensure mass-conservation at best), and on the numerical integration over this air-mass.

10 Finally the proposed method combines advantages that are otherwise mutually exclusive with classical Eulerian or Lagrangian (trajectory based) techniques of transport quantification. This owes to a two-step strategy:

- First the scientifically blind (i.e., systematic), on-line calculation of initialcoordinate tracers, that benefits from the full temporal resolution, dynamical consistency, and sub-grid transport parametrizations, of the mesoscale model driving those tracers.

- Then a scientifically guided, low-cost and flexible post-processing that allows to define air-masses and quantify transports relevantly for each particular phenomenon under consideration.

20 This opens a wide range of applications for studying transports of air-masses or atmospheric pollutants with mesoscale models.

\section{References}

Asencio, N., Stein, J., Chong, M., and Gheusi, F.: Analysis and simulation of local and regional conditions for the rainfall over Lago Maggiore Target Area during MAP IOP 2b, Quart. J. Roy.
ACPD

4, 8103-8139, 2004

Quantification of mesoscale transport

F. Gheusi et al.

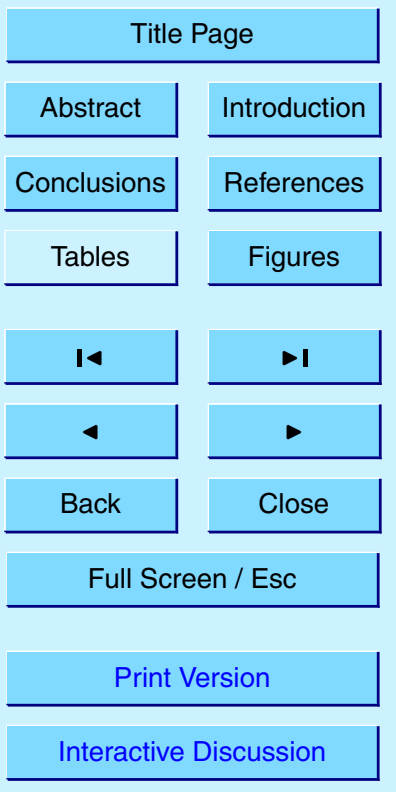

EGU 
Bechtold, P., Kain, J., Bazile, E., Mascart, P., and Richard, E.: A mass flux convection scheme for regional and global models, Quart. J. Roy. Meteor. Soc., 127, 869-886, 2001. 8109

Beekmann, M., Ancellet, G., Blonsky, S., de Muer, D., Ebel, A., Elbern, H., Hendricks, J., Kowol, J., Mancier, C., Sladkovic, R., Smit, H. G. J., Speth, T., Trickl, T., and van Haver, Ph.: Re5 gional and global tropopause fold occurence and related ozone flux across the tropopause, J. Atmos. Chem., 28, 29-44, 1997. 8115

Bougeault, P. and Lacarrère, P.: Parameterization of orography-induced turbulence in a mesobeta scale model, Mon. Wea. Rev., 117, 1870-1888, 1989. 8109

Cathala, M.-L., Pailleux, J., and Peuch, V.-H.: Improving global chemical simulations in the upper troposphere - lower stratopsphere with sequential assimilation of MOZAIC data, Tellus, 55B, 1-10, 2003. 8110

Chattfield, R., Guan, H., Thompson, A., and Witte, J.: Convective lofting links Indian Ocean air pollution to paradoxical South Atlantic ozone maxima, Geophys. Res. Lett., 31, L06103, 5, 2004. 8105

Cousin, F., Tulet, P., and Rosset, R.: Interaction between local and regional pollution during Escompte 2001: impact on surface ozone concentrations (IOP2a and 2b), Atmos. Res., in press, 2004. 8108, 8116, 8117

Crassier, V., Suhre, K., Tulet, P., and Rosset, R.: Development of a reduced chemical scheme for use in mesoscale meteorological models, Atmos. Envir., 34, 2633-2644, 2000. 8117

Cuxart, J., Bougeault, P., and Redelsperger, J.-L.: A turbulence scheme allowing for mesoscale and large-eddy simulations, Quart. J. Roy. Meteor. Soc., 126, 1-30, 2000. 8109

de Forsters, P. and Shine, K.: Radiative forcing and temperature trends from stratospheric ozone changes, J. Geophys. Res., 102(D9), 10841-10855, 1997. 8104

Dethof, A., O'Neill, A., and Slingo, J.: Quantification of the isentropic mass transport across the dynamical tropopause, J. Geophys. Res., 105(D10), 12279-12293, 2000. 8107

Gal-Chen, T. and Sommerville, R.: On the use of a coordinate transformation for the solution of the Navier-Stokes equations, J. Comput. Phys., 17, 209-228, 1975. 8109

Gheusi, F. and Stein, J.: Lagrangian description of air-flows using Eulerian passive tracers, Quart. J. Roy. Meteor. Soc., 128, 337-360, 2002. 8106, 8108, 8110, 8124

so Henne, S., Furger, M., Nyeki, S., Steinbacher, M., Neinnger, B., de Wekker, S., Dommen, J., Spichtinger, N., Stohl, A., and Prévôt, A. S. H.: Quantification of topographic venting of boundary layer air to the free troposphere, Atmos. Chem. Phys., 4, 497-509, 2004,

SRef-ID: 1680-7324/acp/2004-4-497. 8120

ACPD

4, 8103-8139, 2004

\section{Quantification of mesoscale transport}

F. Gheusi et al.

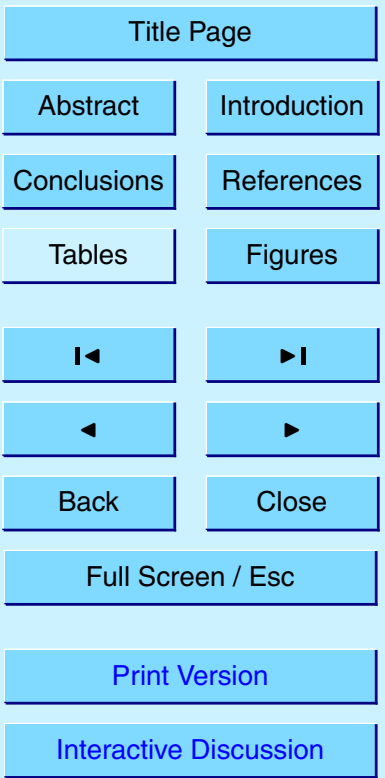

EGU 
IPCC: Climate change 2001: The Scientific Basis, Contribution of Working Group I to the Third Assessment Report of the Intergovernmental Panel on Climate Change, edited by: Houghton, J. T., Ding, Y., Griggs, D. J., Noguer, M., van der Linden, P. J., Dai, X., Maskell, K., and Johnson, C. A., Cambridge University Press, Cambridge, United Kingdom and New 5 York, NY, USA, 881, 2001. 8104, 8105

Issartel, J.-P. and Baverel, J.: Inverse transport for the verification of the Comprehensive Nuclear Test Ban Treaty, Atmos. Chem. Phys., 3, 475-486, 2003, SRef-ID: 1680-7324/acp/2003-3-475. 8122

Kessler, E.: On the distribution and continuity of water substance in atmospheric circulation, Meteor. Monogr., 46, 165-170, 1969. 8109

Kowol-Santen, J., Elbern, H., and Ebel, A.: Estimation of cross-tropopause airmass fluxes at midlatitudes: comparison of different numerical methods and meteorological situations, Mon. Wea. Rev., 128, 4045-4057, 2000. 8106

Lafore, J., Stein, J., Asencio, N., Bougeault, P., Ducrocq, V., Duron, J., Fischer, C., Héreil, P., Mascart, P., Redelsperger, J., Richard, E., and Vilà-Guerau de Arellano, J.: The Meso-NH atmospheric simulation system, Part I: Adiabatic formulation and control simulations, Ann. Geophys., 16, 90-109, 1998, SRef-ID: 1432-0576/ag/1998-16-90. 8109

Micley, L., Murti, P., Jacob, D., Logan, J., Koch, D., and Rind, D.: Radiative forcing from tropospheric ozone calculated with a unified chemistry-climate model, J. Geophys. Res., 104(D23), $30153-30172,1999.8104$

Millan, M., Salvador, R., Mantilla, E., and Kallos, G.: Photooxidant dynamics in the Mediterranean basin in summer: results from European research projects, J. Geophys. Res., 102(D7), 8811-8823, 1997. 8120

Morcrette, J.-J.: Radiation and cloud radiative properties in the European Center for Medium range Weather Forcasts forecasting system, J. Geophys. Res., 96, 9121-9132, 1991. 8109

Nilsson, E., Rannik, U., Kulmala, M., Buzorius, G., and O'Dowd, C.: Effects of continental boundary layer evolution, convection, turbulence and entrainment, on aerosol formation, Tellus, 53(4), 441-461, 2001. 8125

30 Noilhan, J. and Planton, S.: A simple parametrization of land surface precessus for meteorological models, Mon. Wea. Rev., 117, 536-549, 1989. 8109

Nédélec, P., Cammas, J.-P., Thouret, V., Athier, G., Cousin, J.-M., Legrand, C., Abonnel, C., Lecoeur, F., Cayez, G., and Marizy, C.: An improved infrared carbon monoxide analyser

ACPD

4, 8103-8139, 2004

\section{Quantification of mesoscale transport}

F. Gheusi et al.

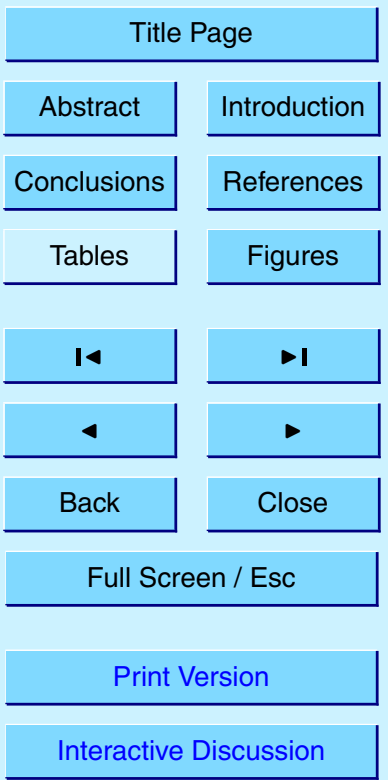

EGU 
for routine measurements aboard commercial Airbus aircraft: technical validation and first scientific results of the MOZAIC III programme, Atmos. Chem. Phys., 3, 1551-1564, 2003, SRef-ID: 1680-7324/acp/2003-3-1551. 8112

Pinty, J.-P. and Jabouille, P.: A mixed-phase cloud parametrization for use in mesoscale non5 hydrostatic model: simulations of a squall-line and of orographic precipitations, AMS Conf. Cloud Phys., Everett, WA, USA, 217-220, 1998. 8112

Sauvage, B., Thouret, V., Cammas, J., Gheusi, F., Athier, G., and Nédélec, P.: Tropospheric ozone over Equatorial Africa: regional aspects from the MOZAIC data, Atmos. Chem. Phys. Discuss., 4, 3285-3331, 2004,

10 SRef-ID: 1680-7375/acpd/2004-4-3285. 8105

Schoeberl, M. and Newman, P.: A multiple-level trajectory analysis of vortex filaments, J. Geophys. Res., 100(D12), 25801-25815, 1995. 8111

Sprenger, M. and Wernli, H.: A northern hemisheric climatology of cross-tropopause exchange for the ERA15 time period (1979-1993), J. Geophys. Res., 108(D12), 8521, 2003. 8106

Stockwell, W., Kirchner, F., Kuhn, M., and Seefeld, S.: A new mechanism for regional atmospheric chemistry modeling, J. Geophys. Res., 102, 25847-25879, 1997. 8117

Stohl, A., Wernli, H., James, P., Bourqui, M., Forster, C., Liniger, M., Seibert, P., and Sprenger, M.: A new perspective of stratosphere-troposphere exchange, Bull. Am. Meteor. Soc., 84(11), 1565-1573, 2003. 8106

Stohl, A., Cooper, O., and James, P.: A cautionary note on the use of meteorological analysis fields for quantifying atmospheric mixing, J. Atmos. Sci., 61, 1446-1453, 2004. 8106, 8123

Thépaut, J., Alary, P., Caille, P., Casse, V., Geley, J.-F., Moll, P., Pailleux, J., Piriou, J.-M., Peuch, D., and Taillefer, F.: The operational global data assimilation system at Météo-France, HIRLAM 4 Workshop on variational analysis in limited area models, Toulouse, France, HIRLAM 4 Project, 25-31, 1998. 8109

Tulet, P., Crassier, V., Solmon, F., Guedalia, D., and Rosset, R.: Regional pollution modelling - Description of the Meso-NH-C model and application to a transboundary pollution episode between northern France and southern England, J. Geophys. Res., 108, 4021, doi:10.1029/2000JD000 301, 2003. 8117

von Kuhlmann, R., Lawrence, M., Crutzen, P., and Rasch, P.: A model for studies of tropospheric ozone and nonmethane hydrocarbons: Model evaluation of ozone-related species, J. Geophys. Res., 108(D23), 4729, doi:10.1029/2002JD003348, 2003. 8112

Wei, M.-Y.: A new formulation of the exchange of mass and trace constituents between the
ACPD

4, 8103-8139, 2004

\section{Quantification of mesoscale transport}

F. Gheusi et al.

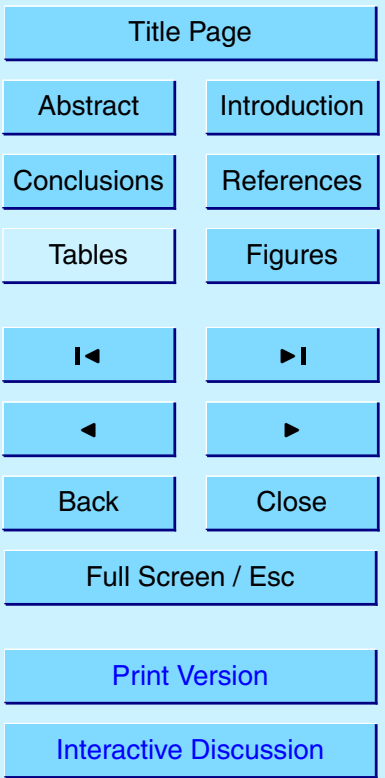

EGU 
stratophere and troposphere, J. Atmos. Sci., 20, 3079-3086, 1987. 8106

Wirth, V. and Egger, J.: Diagnosing extratropical synoptic-scale stratosphere-troposphere exchange: a case study, Quart. J. Roy. Meteor. Soc., 125, 635-655, 1999. 8106

\section{ACPD}

4, 8103-8139, 2004

\section{Quantification of mesoscale transport}

F. Gheusi et al.

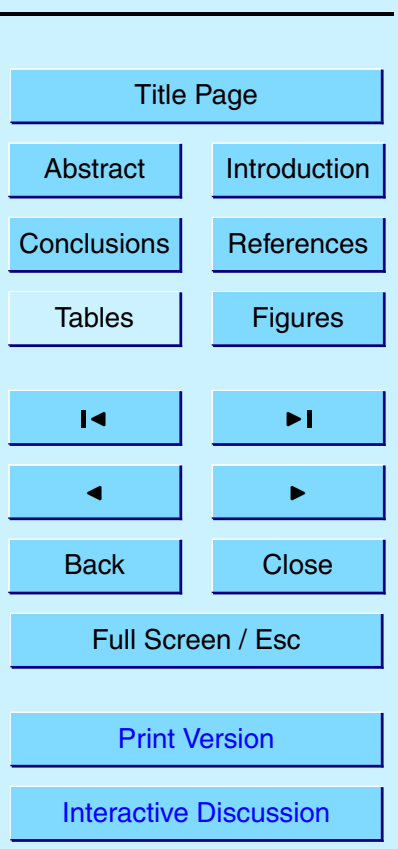




\section{ACPD}

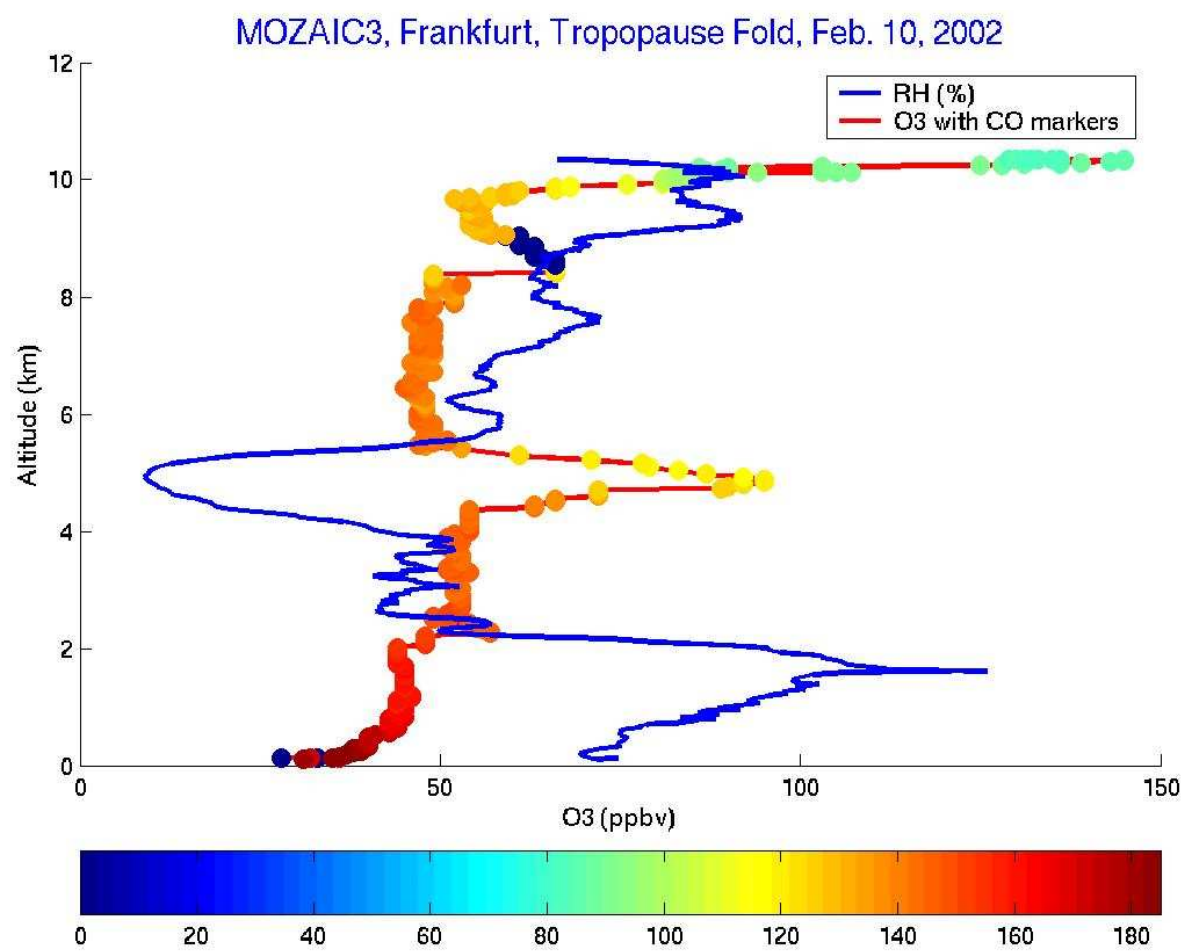

4, 8103-8139, 2004

\section{Quantification of mesoscale transport}

F. Gheusi et al.

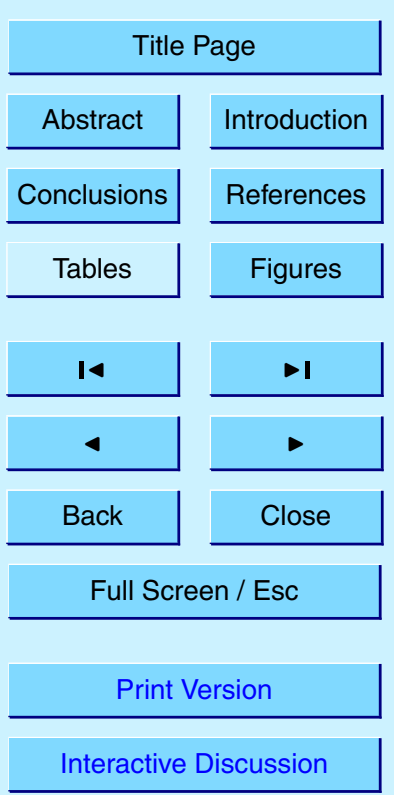

Fig. 1. MOZAIC profiles of relative humidity (blue) and $\mathrm{O}_{3}$ mixing-ratio (colored). The ozone curve is colored according to the $\mathrm{CO}$ mixing-ratio (bottom colorscale in ppbv). The instrumented aircraft took off from Frankfurt airport $\left(50.0^{\circ} \mathrm{N}, 8.6^{\circ} \mathrm{E}\right)$ on 10 February 2002, $12: 34$ UTC and reached its ceiling altitude $(10350 \mathrm{~m}) 30 \mathrm{mn}$ later over the Netherlands (see Fig. 2b). 


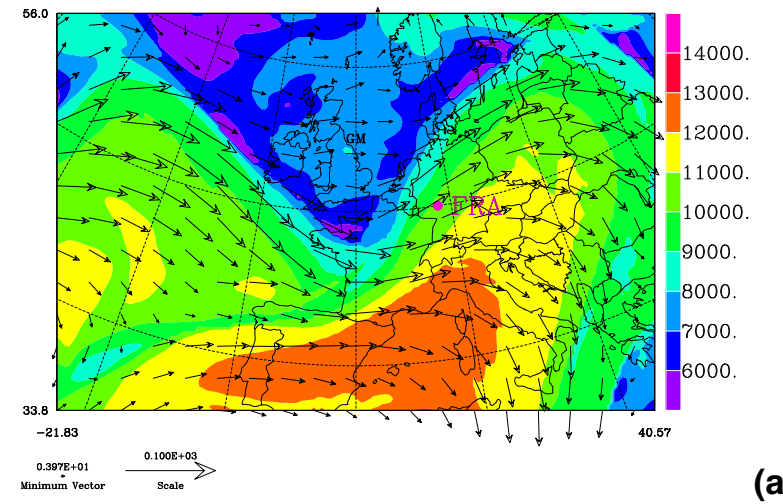

4, 8103-8139, 2004

Geopotential $(\mathrm{m})$ and wind $(\mathrm{m} / \mathrm{s}) @ 1.5 \mathrm{PVU}$

(a)

\section{Quantification of mesoscale transport}

F. Gheusi et al.

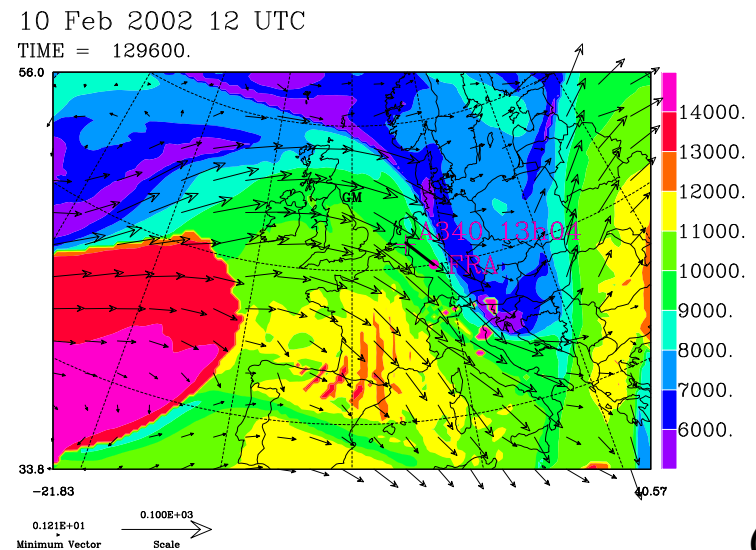

(b)

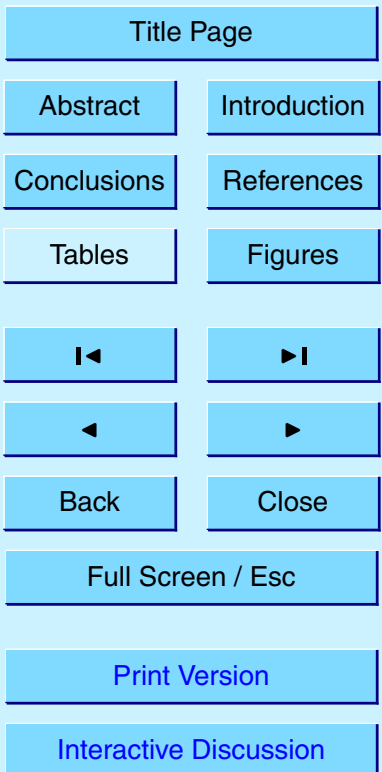

Fig. 2. Simulated altitude and wind on the 1.5 PVU surface: (a) $18 \mathrm{~h}$ and (b) $36 \mathrm{~h}$ after model start. 'FRA' marks the location of Frankfurt airport and 'A340' (in b) that of the MOZAIC aircraft EGU at 13:04 UTC just when it reached its ceiling $(10350 \mathrm{~m})$. 


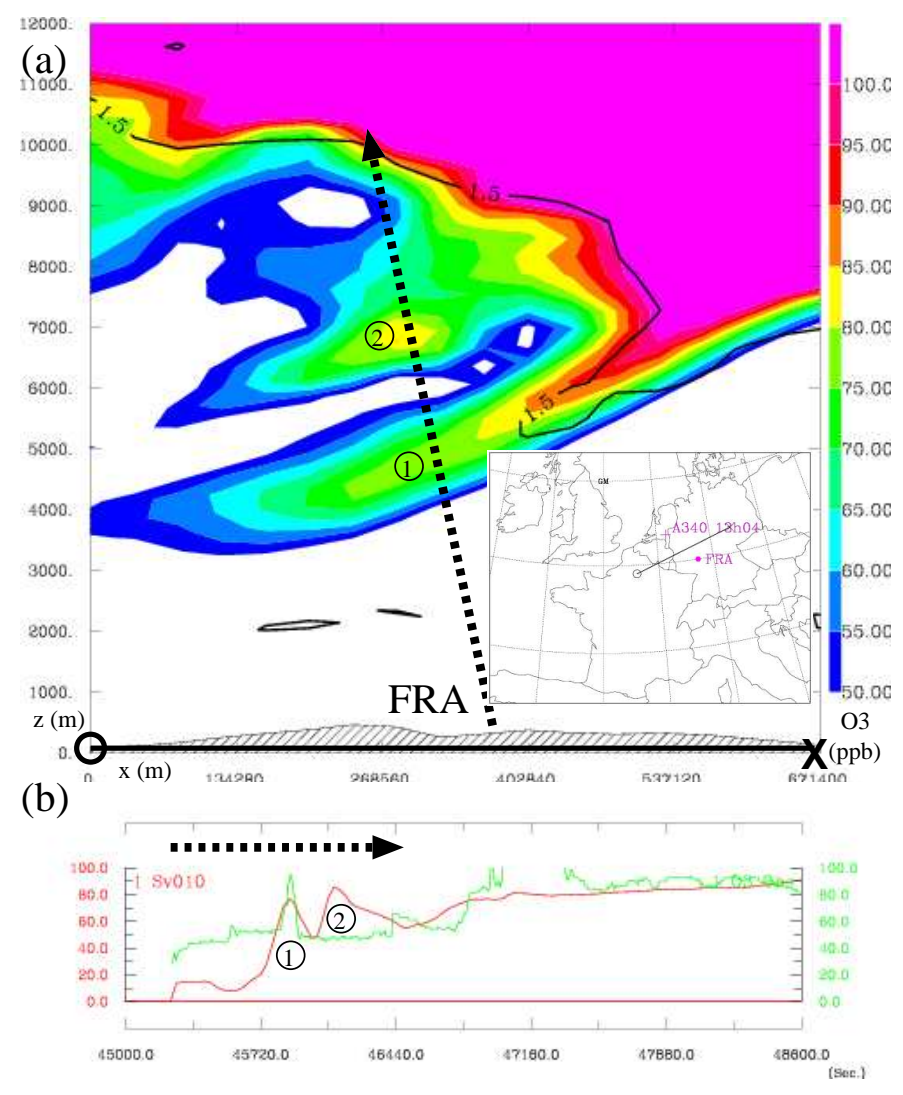

Fig. 3. (a) Vertical cross-section (indicated in the embedded map by the segment ended with a circle and a cross) of the simulated ozone mixing ratio (colorscale in ppbv) and $\mathrm{PV}$ (solid contour 1.5 PVU) on 10 February 2002, 12:00 UTC. (b) Ozone mixing-ratio (ppbv) along the A340 flightpath for an hour starting short before take off (at $t=45250 \mathrm{~s}$ ): MOZAIC measurements (green curve) and MesoNH simulation (red curve). The dashed arrow in both panels sketches the aircraft ascent. Marks "1" and "2" help to connect the simulated $\mathrm{O}_{3}$-peaks in (b) with the $\mathrm{O}_{3}$ field in (a).

\section{ACPD}

4, 8103-8139, 2004

\section{Quantification of mesoscale transport}

F. Gheusi et al.

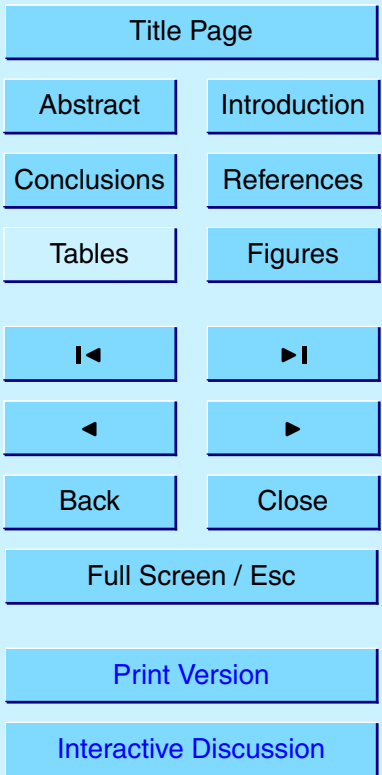

EGU 


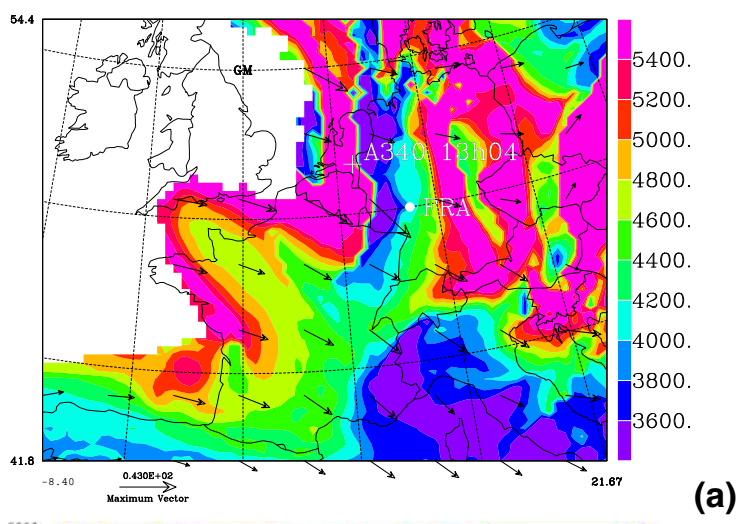

ACPD

4, 8103-8139, 2004

\section{Quantification of mesoscale transport}

F. Gheusi et al.
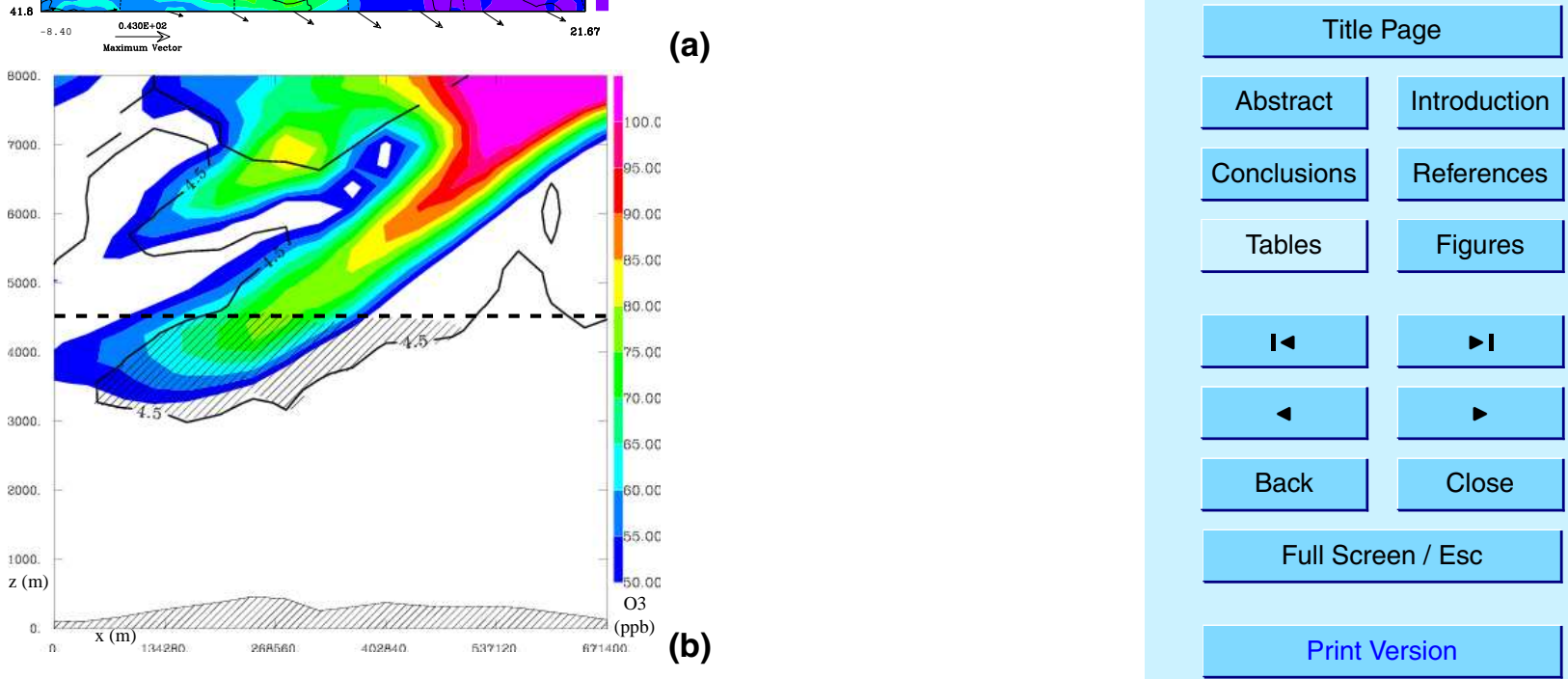

Fig. 4. 10 February 2002 at 12:00 UTC: (a) Colorscale (in m): Altitude of the points the isosurface $z_{0}=4500 \mathrm{~m}$ (i.e., current altitude of the air parcels that were at $z=4500 \mathrm{~m}$ at the initial instant $18 \mathrm{~h}$ before). (b) Vertical cross-section as in Fig. 3: ozone mixing-ratio (colorscale in ppbv) and initial altitude $z_{0}=4500 \mathrm{~m}$ (solid isocontour). 


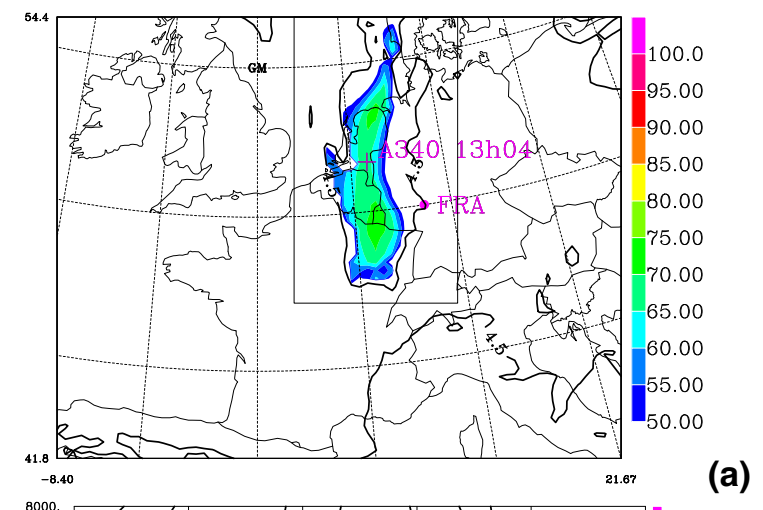

ACPD

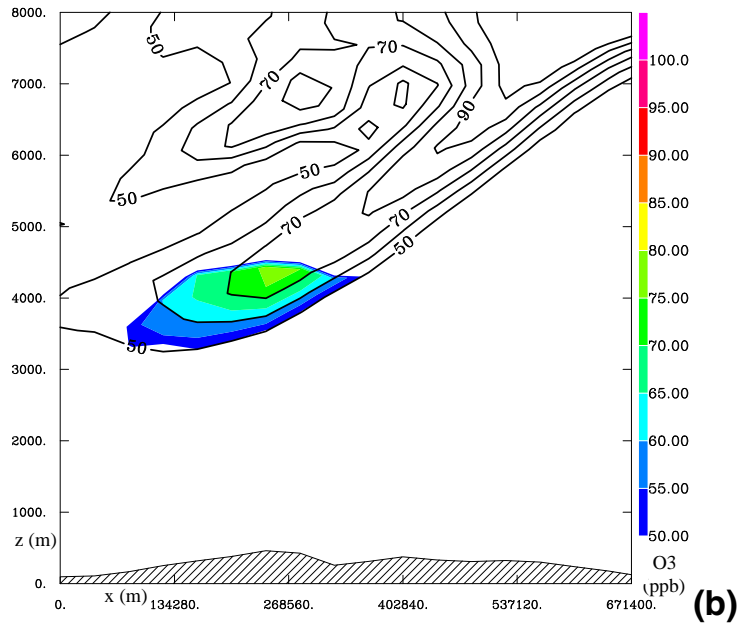

4, 8103-8139, 2004

\section{Quantification of mesoscale transport}

F. Gheusi et al.

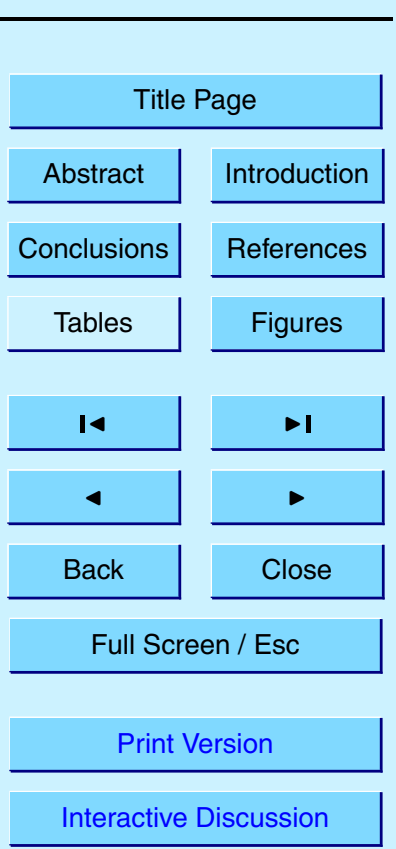

Fig. 5. 10 February 2002 at 12:00 UTC: (a) Ozone mixing-ratio only for the selected descending air-mass $\left(\left[\mathrm{O}_{3}\right]_{\downarrow}\right.$, see text) at $z=4000 \mathrm{~m}$ (colorscale in ppbv) and initial altitude contour $z_{0}=4500 \mathrm{~m}$ at the same altitude level. The frame indicates the domain for the final geographical selection (see text). (b) Vertical cross-section as in Fig. 3: ozone mixing-ratio only for the selected air-mass (colorscale in ppbv). Solid contours (every ten ppbv above 50) recall the whole ozone distribution displayed in Fig. $4 \mathrm{~b}$. 


\section{ACPD}

23 June 2001, 15 UTC

Geopotential (m) and wind vectors @ $500 \mathrm{hPa}$

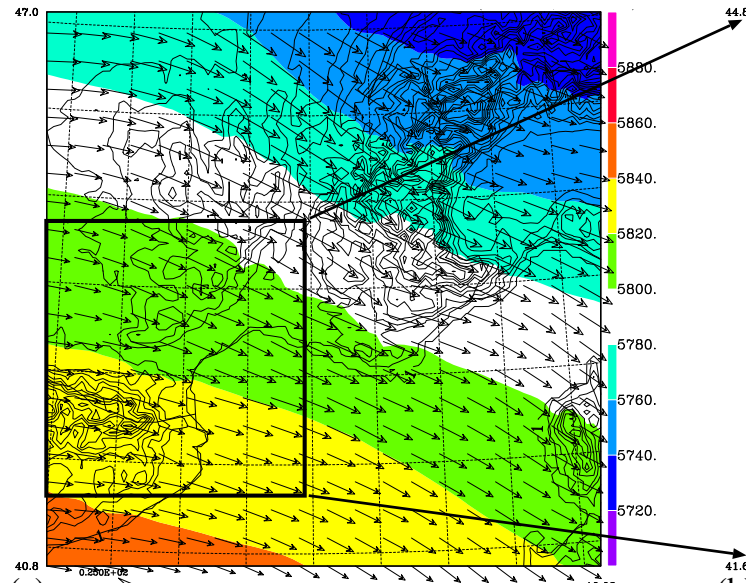

(a)

(b) $\stackrel{0.2000+102}{2}$
23 June 2001, 15 UTC

Wind vectors@50m AGL,TKF@ @

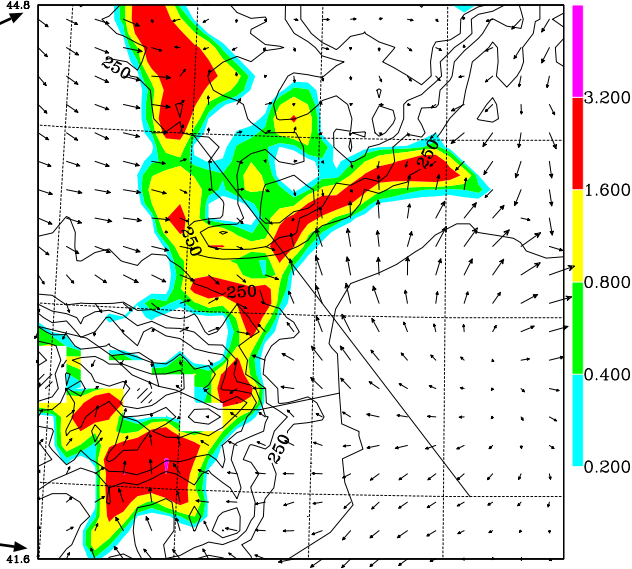

4.93

Fig. 6. (a) Mid-tropospheric ( $500 \mathrm{hPa}$ ) flux on 23 June 2001, 15:00 UTC. The box delimits the subdomain used for panel (b) and some other figures in the following. (b) Wind field (vectors every $36 \mathrm{~km}$ ) $50 \mathrm{~m}$ above the ground level (AGL) and turbulent kinetic energy (TKE in $\left.\mathrm{m}^{2} / \mathrm{s}^{2}\right)$ at the altitude level $z=2000 \mathrm{~m}$.

4, 8103-8139, 2004

\section{Quantification of mesoscale transport}

F. Gheusi et al.

\begin{tabular}{|c|c|}
\hline \multicolumn{2}{|c|}{ Title Page } \\
\hline Abstract & Introduction \\
\hline Conclusions & References \\
\hline Tables & Figures \\
\hline 14 & $\rightarrow 1$ \\
\hline 4 & $\triangleright$ \\
\hline Back & Close \\
\hline \multicolumn{2}{|c|}{ Full Screen / Esc } \\
\hline \multicolumn{2}{|c|}{ Print Version } \\
\hline Interact & ussion \\
\hline
\end{tabular}

EGU 


\section{ACPD}

03 (ppb), 23 June 2001, 15 UTC TKE $>0.2$

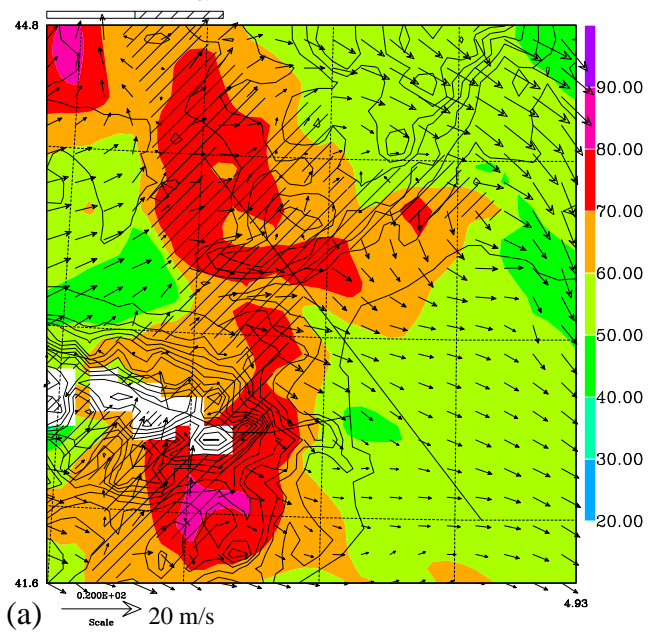

03 (ppb), 23 June 2001, 20 UTC

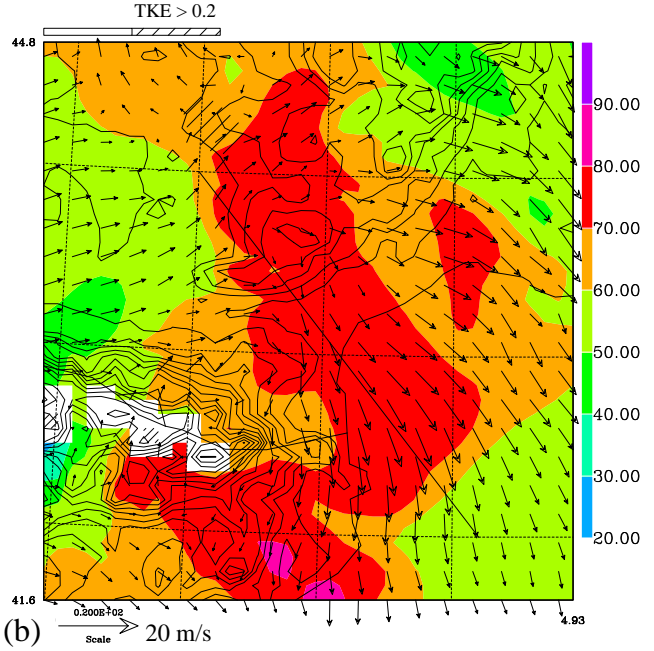

Fig. 7. Ozone mixing-ratio (colorscale in ppbv), turbulent kinetic energy exceeding $0.2 \mathrm{~m}^{2} / \mathrm{s}^{2}$ (hatched area) and wind field (vectors every $18 \mathrm{~km}$ ) at $z=2000 \mathrm{~m}$ on 23 June 2001 at (a) 15:00 UTC, (b) 20:00 UTC.

4, 8103-8139, 2004

Quantification of mesoscale transport

F. Gheusi et al.

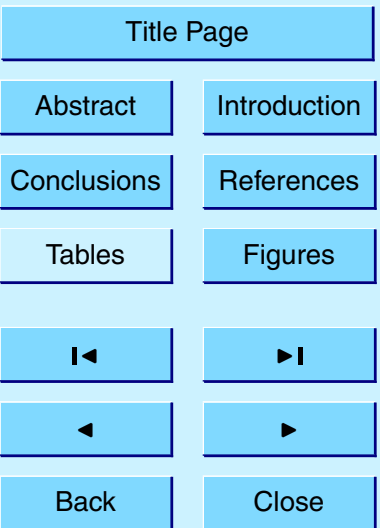

Full Screen / Esc

Print Version

Interactive Discussion 
23 June 200115 UTC, Boundary Layer @ z=2000m

(a)

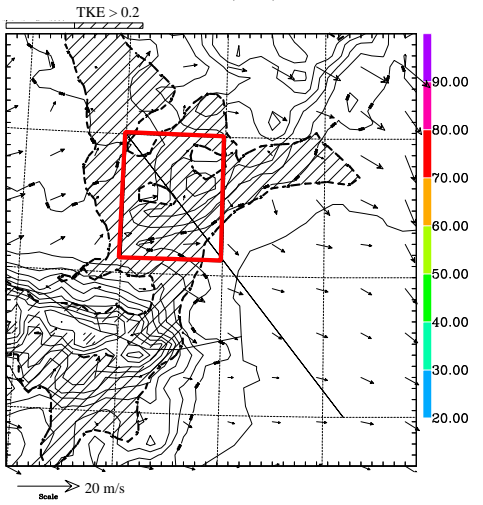

23 June 200118 UTC, 03 (ppb) in the selected airmas

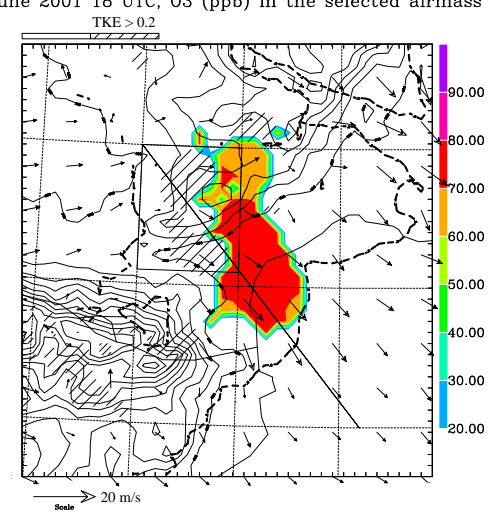

23 June 200116 UTC, 03 (ppb) in the selected airmass TKE $>0.2$

(b)

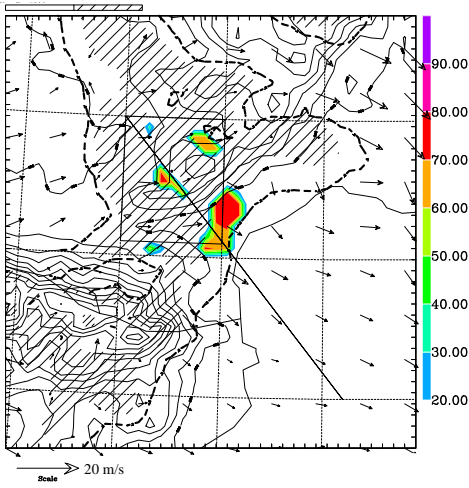

scale 20120 UTC

$$
\text { (d) }
$$

(d)

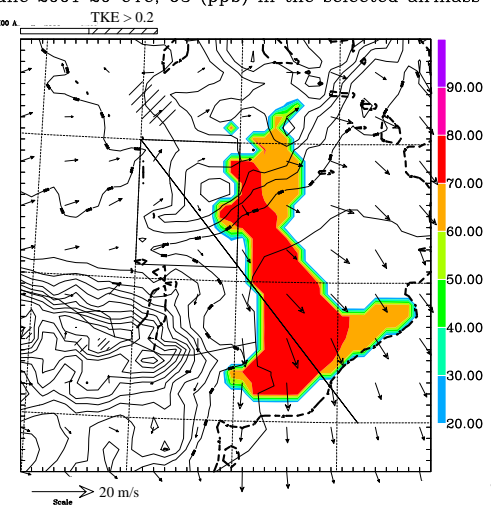

ACPD

4, 8103-8139, 2004

\section{Quantification of mesoscale transport}

F. Gheusi et al.

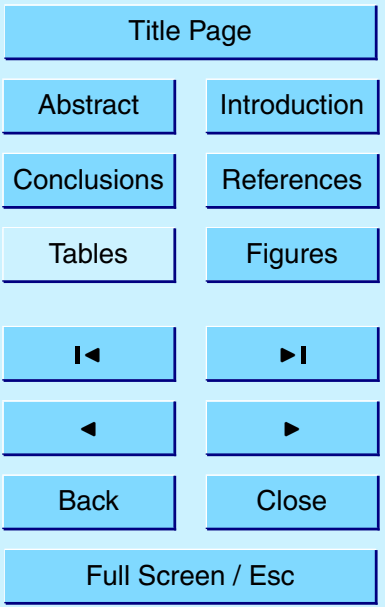

Fig. 8. All panels (horizontal sections at $z=2000 \mathrm{~m}$, on 23 June 2001 at (a) 15:00 UTC, (b) 16:00 UTC, (c) 18:00 UTC and (d) 20:00 UTC): wind field (vectors every $36 \mathrm{~km}$ ); turbulent kinetic energy $T K E>0.2 \mathrm{~m}^{2} / \mathrm{s}^{2}$ (hatched area); initial turbulent kinetic energy $T K E_{0}=0.2 \mathrm{~m}^{2} / \mathrm{s}^{2}$ Persion with reference time $t_{0}=15: 00$ UTC (dashed contour, see text for explanation). The diagonal thin solid line marks the vertical cross-sections displayed in Fig. 9. The box (emphasized in red in panel a) delimits the origin area used for the airmass selection (see text). (b-d) Colorscale: ozone mixing-ratio (ppbv) in the selected airmass (see text), zero elsewhere. 

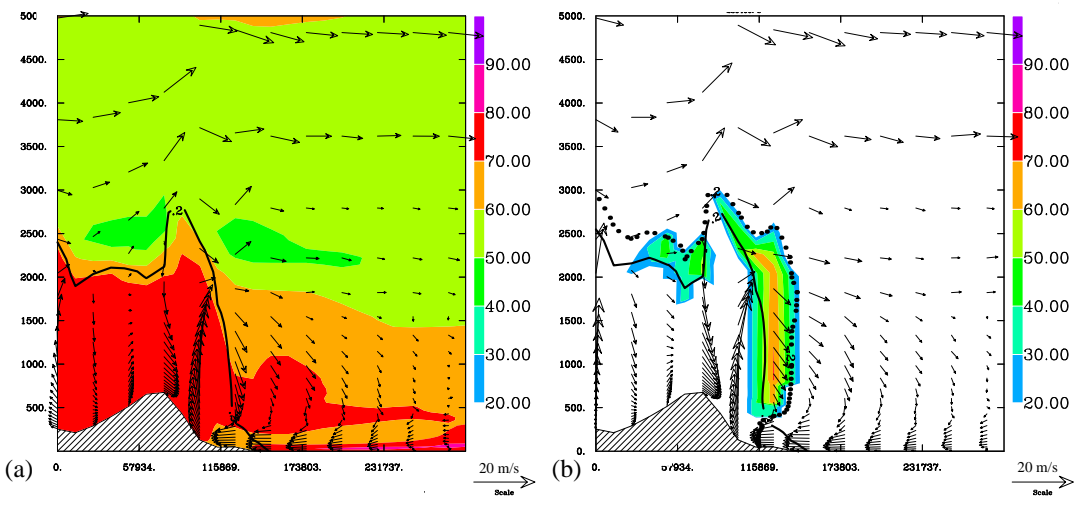

23 June 200118 UTC, O3 (ppb) in the selected airmass 23 June 200120 UTC, 03 (ppb) in the selected airmass
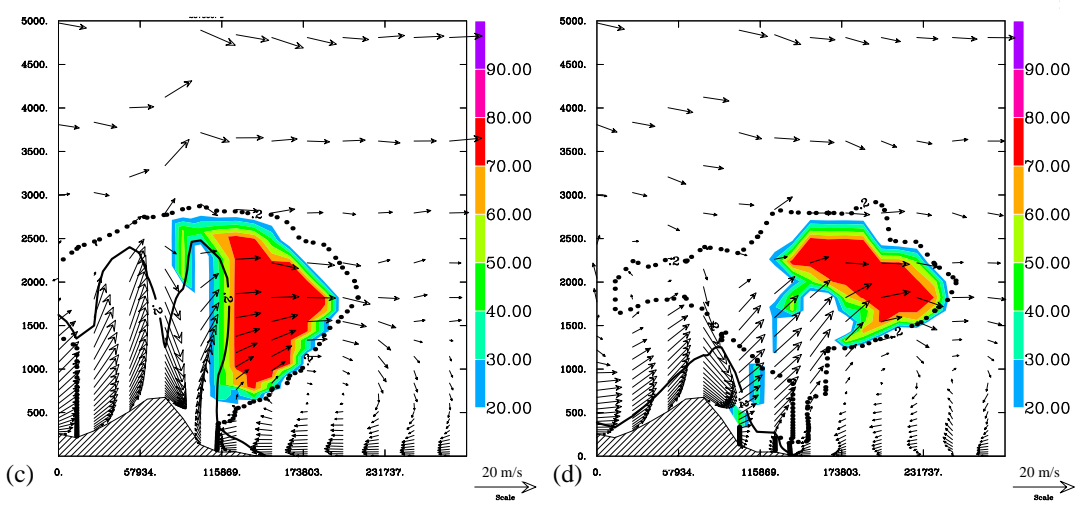

Fig. 9. All panels (NW-SE vertical section, see Fig. 8 for location): wind component in the section plane (vectors every 2 grid-points); turbulent kinetic energy $T K E=0.2 \mathrm{~m}^{2} / \mathrm{s}^{2}$ (solid contour). (a) Colorscale: ozone mixing-ratio (ppbv). (b-d) initial turbulent kinetic energy $T K E_{0}=0.2 \mathrm{~m}^{2} / \mathrm{s}^{2}$ with reference time $t_{0}=15: 00$ UTC (dashed contour, see text for explanation). Colorscale: ozone mixing-ratio (ppbv) in the selected airmass (see text), zero elsewhere.

\section{4, 8103-8139, 2004}

\section{Quantification of mesoscale transport}

F. Gheusi et al.

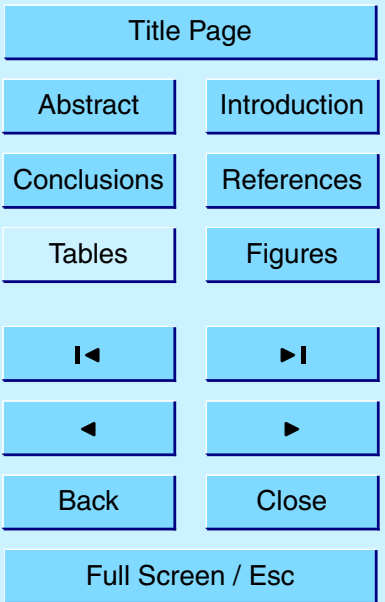

Print Version

Interactive Discussion

EGU 